Enhanced mechanical properties in cellulose nanocrystal-poly(oligo ethylene glycol methacrylate) injectable nanocomposite hydrogels through control of physical and chemical cross-linking

Kevin J. De France, Katelyn J. W. Chan, Emily D. Cranston, Todd Hoare*

DOI: 10.1021/acs.biomac.5b01598

Reprinted with permission from (De France, K. J.; Chan, K. J. W.; Cranston, E. D.; Hoare, T. Biomacromolecules 2016, 17 (2), 649-660.). Copyright (2016) American Chemical Society. 


\title{
Enhanced mechanical properties in cellulose nanocrystal-poly(oligo ethylene glycol methacrylate) injectable nanocomposite hydrogels through control of physical and chemical cross-linking
}

\author{
Kevin J. De France, Katelyn J. W. Chan, Emily D. Cranston, Todd Hoare*
}

Department of Chemical Engineering, McMaster University, 1280 Main Street West, Hamilton, ON L8S 4L8, Canada

\footnotetext{
* To whom correspondence should be addressed
}

E-mail: hoaretr@mcmaster.ca 


\section{ABSTRACT}

While injectable hydrogels have several advantages in the context of biomedical use, their generally weak mechanical properties often limit their applications. Herein we describe in situgelling nanocomposite hydrogels based on poly(oligoethylene glycol methacrylate) (POEGMA) and rigid rod-like cellulose nanocrystals (CNCs) that can overcome this challenge. By physically incorporating CNCs into hydrazone cross-linked POEGMA hydrogels, macroscopic properties including gelation rate, swelling kinetics, mechanical properties, and hydrogel stability can be readily tailored. Strong adsorption of aldehyde and hydrazide modified POEGMA precursor polymers onto the surface of CNCs promotes uniform dispersion of CNCs within the hydrogel, imparts physical cross-links throughout the network, and significantly improves mechanical strength overall, as demonstrated by quartz crystal microbalance gravimetry and rheometry. When POEGMA hydrogels containing mixtures of long and short ethylene oxide side chain precursor polymers were prepared, transmission electron microscopy reveals that phase segregation occurs with CNCs hypothesized to preferentially locate within the stronger adsorbing short side chain polymer domains. Incorporating as little as 5 wt \% CNCs results in dramatic enhancements in mechanical properties (up to 35-fold increases in storage modulus) coupled with faster gelation rates, decreased swelling ratios, and increased stability versus hydrolysis. Furthermore, cell viability can be maintained within 3D culture using these hydrogels independent of the CNC content. These properties collectively make POEGMA-CNC nanocomposite hydrogels of potential interest for various biomedical applications including tissue engineering scaffolds for stiffer tissues or platforms for cell growth. 


\section{INTRODUCTION}

Hydrogels have been widely explored as promising biomaterial candidates for cell scaffolds and drug delivery vehicles due to their high water content, controllable porosity, generally acceptable biocompatibility in a range of biological environments, and their generally facile chemical tailorability. ${ }^{1-4}$ While a variety of physical, ${ }^{5}$ chemical $^{6}$ or ion-mediated ${ }^{7}$ gelation methods have been applied to create hydrogels, recent advances in in situ-gelling chemistries (including largely bio-orthogonal click chemistry-based approaches ${ }^{6,8-10}$ ) have made hydrogels particularly translatable to biomedical applications, eliminating the need for gelation initiators such as heat, excessive agitation, chemical activators, UV light, or $\mathrm{pH}$ changes while enabling minimally invasive delivery to targeted sites in the body. Moreover, these injectable materials can be engineered to display tunable biodegradation under different environmental conditions depending on the chemistry used to form the cross-links. ${ }^{9,11,12}$ However, injectable hydrogels are often limited by a relatively low elastic modulus, ${ }^{13-16}$ limiting their utility in applications demanding at least a degree of mechanical strength (e.g. engineering of stiffer tissues such as cartilage,${ }^{17}$ implantation in high-shear environments, ${ }^{18}$ or spinal applications $\left.{ }^{19}\right)$.

Recently, poly (oligo ethylene glycol methacrylate) (POEGMA)-based hydrogels have garnered attention for biomedical applications due to their demonstrated in vivo tolerability, ease of functionalization, potential for rapid gelation, and optional thermoresponsive properties. ${ }^{8,20,21}$ Unlike poly(ethylene glycol) (PEG), which can only be end-group functionalized, the free radical (co)polymerization method used to produce POEGMA enables the incorporation of a range of reactive comonomers or cross-linkers, facilitating production of pre-gel precursor polymers with a range of desired chemistries, cross-link densities, and molecular weights. We have previously reported extensively on modular POEGMA hydrogels cross-linked via hydrazone bonds, formed 
by reactive extrusion of aldehyde and hydrazide-functionalized precursor polymers. ${ }^{822-26}$ Hydrogel properties including the lower critical solution temperature (LCST), cross-link density, swelling ratio, and cell adhesion can be modified by varying the ethylene oxide side chain length, ${ }^{24}$ combining multiple precursor polymers, ${ }^{22}$ or introducing hydrophobic domains into the precursor polymers. ${ }^{26}$ However, the mechanical strength of these materials remains limited; more specifically, in the context of the highly protein and cell-repellent POEGMA hydrogels based on long oligo(ethylene glycol) side chains, even highly functionalized precursor polymers (30 mol $\%$ hydrazide or aldehyde-bearing repeat units) lead to hydrogels with only moderate mechanical strength ( $1 \mathrm{kPa}$ shear storage modulus).

CNCs have been investigated as reinforcing agents for a variety of polymeric systems due to their large aspect ratio, high Young's modulus (over $100 \mathrm{GPa}$ ) and recent commercial availability. ${ }^{27,28}$ Based on their demonstrated low cytotoxicity ${ }^{29-35}$ they have also recently gained interest in biomedical applications including tissue engineering, drug delivery and bioimaging. ${ }^{30,36-38}$ To date, CNCs have been used as a reinforcing component in hydrogels ${ }^{5}$ (primarily polyacrylamide-based materials ${ }^{39-41}$ ) and other biocomposite materials including electrospun poly(lactic acid) ${ }^{42}$ and cellulose fiber scaffolds. ${ }^{43}$ However, a lack of injectability, a poor understanding of $\mathrm{CNC}$ distribution throughout the nanocomposite, and underwhelming increases in mechanical performance limits the application of these systems. While our recently reported work on hydrazone cross-linked dextran/carboxymethyl cellulose (CMC) polysaccharide hydrogels reinforced with both unmodified and aldehyde-functionalized CNCs achieved the goals of injectability and uniform $\mathrm{CNC}$ distribution, the mechanics remained too low for many applications; a maximum increase in elastic modulus of $140 \%$ was demonstrated, 
with a decrease in modulus observed at CNC loadings above $0.5 \mathrm{wt} \%$ (hypothesized to relate to the presence of CNCs compromising the ability of dextran and CMC to cross-link). ${ }^{44}$

Herein, we demonstrate how simple physical entrapment of CNCs within injectable POEGMA-based hydrogels can lead to injectable hydrogels with orders-of-magnitude increases in mechanical properties. POEGMA precursor polymers strongly adsorb to CNCs (imparting physical cross-links) and leading to both excellent dispersibility of CNCs within the hydrogel as well as remarkable enhancements in gel mechanics relative to previously reported $\mathrm{CNC}$-hydrogel nanocomposites. Concurrently, the POEGMA-CNC interactions are demonstrated to drive significant changes in other gel properties including gelation rate, swelling, and degradation kinetics, even at very low overall CNC loadings $(<5 \mathrm{wt} \%)$. Together, these properties may offer opportunities for rational hydrogel design to achieve a wide variety of gel properties amenable to many potential biomedical applications.

\section{EXPERIMENTAL}

\section{Materials.}

Di-(ethylene glycol) methyl ether methacrylate $\left(\mathrm{M}(\mathrm{EO})_{2} \mathrm{MA}, \mathrm{n}=2 \mathrm{EO}\right.$ repeat units, Sigma Aldrich, 95\%) and oligo(ethylene glycol) methyl ether methacrylate with an average numberaverage molecular weight of $500 \mathrm{~g} \mathrm{~mol}^{-1}\left(\mathrm{OEGMA}_{500}, \mathrm{n}=8-9 \mathrm{EO}\right.$ repeat units, Sigma Aldrich, 95\%) were purified through a column of basic aluminum oxide (Sigma Aldrich, type CG-20) to remove inhibitors. Functional monomer N-(2,2-dimethoxyethyl)-methacrylamide (DMAEAm) was synthesized as described previously. ${ }^{23}$ Acrylic acid (AA, Sigma Aldrich, 99\%), 2,2azobisisobutyric acid dimethyl ester (AIBMe, Wako Chemicals, 98.5\%), adipic acid dihydrazide 
(ADH, Alfa Aesar, 98\%), N'-ethyl-N-(3-dimethylaminopropyl)-carbodiimide (EDC,

Carbosynth, Compton CA, commercial grade), thioglycolic acid (TGA, Sigma Aldrich, 98\%), sodium hydroxide (EMD Millipore Germany), sodium chloride (Sigma Aldrich, $\geq 99.5 \%$ ), hydrochloric acid (LabChem Inc., $1 \mathrm{M}$ ), dioxane (Caledon Laboratory Chemicals, reagent grade) and sulfuric acid (Sigma Aldrich, 95-98\%) were all used as received. Whatman cotton ashless filter aid (CAT No. 1703-050, GE Healthcare Canada) was used as the cellulose source. 3T3 Mus musculus mouse fibroblast cells were obtained from ATCC: Cedarlane Laboratories (Burlington, ON, Canada) and cultured in Dulbecco's modified Eagle medium - high glucose (DMEM) supplemented with $10 \%$ fetal bovine serum (FBS) and 1\% penicillin streptomycin (PS). TrypsinEDTA, and a LIVE/DEAD assay kit were purchased from Invitrogen Canada (Burlington, ON, Canada). Resazurin sodium salt was purchased from Sigma Aldrich. For all experiments Millipore Milli-Q grade distilled deionized water (DIW, $18.2 \mathrm{M} \Omega \mathrm{cm}$ resistivity) was used.

Synthesis of hydrazide-functionalized poly(oligo ethylene glycol methacrylate) $\left(\mathrm{PO}_{x} \mathrm{H}_{30}\right)$.

Precursor polymers $\mathrm{PO}_{10} \mathrm{H}_{30}\left(10 \mathrm{~mol} \%\right.$ OEGMA $\left.500 / 90 \mathrm{~mol} \% \mathrm{M}(\mathrm{EO})_{2} \mathrm{MA}\right)$ and $\mathrm{PO}_{100} \mathrm{H}_{30}$ $\left(100 \mathrm{~mol}_{\%} \mathrm{OEGMA}_{500}\right)$ were synthesized to have $30 \mathrm{~mol} \%$ hydrazide-functionality (denoted as $\left.\mathrm{H}_{30}\right)$ as described previously. ${ }^{24}$ Briefly, AIBMe $(74 \mathrm{mg}), \mathrm{M}(\mathrm{EO})_{2} \mathrm{MA}\left(6.2 \mathrm{~g}\right.$ for $\mathrm{PO}_{10} \mathrm{H}_{30}, 0 \mathrm{~g}$ for $\left.\mathrm{PO}_{100} \mathrm{H}_{30}\right)$, OEGMA $500\left(1.8 \mathrm{~g}\right.$ for $\mathrm{PO}_{10} \mathrm{H}_{30}, 8.0 \mathrm{~g}$ for $\left.\mathrm{PO}_{100} \mathrm{H}_{30}\right)$, AA $(1050 \mu \mathrm{L} ; 30 \mathrm{~mol} \%$ to total added OEGMA $\mathrm{A}_{500}+\mathrm{M}(\mathrm{EO})_{2} \mathrm{MA}$ for $\mathrm{PO}_{10} \mathrm{H}_{30}, 550 \mu \mathrm{L} ; 30 \mathrm{~mol} \%$ to total added OEGMA $\mathrm{A}_{500}$ for $\left.\mathrm{PO}_{100} \mathrm{H}_{30}\right)$ and TGA $(150 \mu \mathrm{L}, 10 \mathrm{wt} \%$ in dioxane) were added to a $250 \mathrm{~mL}$ round bottom flask. $40 \mathrm{~mL}$ of dioxane was added to the reaction mixture, which was then purged with nitrogen at ambient conditions for at least $20 \mathrm{~min}$. The reaction was allowed to proceed for $4 \mathrm{~h}$ at $75{ }^{\circ} \mathrm{C}$ under magnetic stirring, after which the flask was cooled. After solvent evaporation, DIW (200 $\mathrm{mL}$ ) was added to the oligo(ethylene glycol) methyl ether methacrylate/acrylic acid copolymer 
solution. $\mathrm{ADH}$ (8.66 g) was added and the solution $\mathrm{pH}$ was adjusted to $4.8 \pm 0.1 \mathrm{using} 1 \mathrm{M} \mathrm{HCl}$. EDC (3.87 g) was then added to mediate grafting of hydrazide groups to AA residue carboxylic acid groups, maintaining the $\mathrm{pH}$ at $4.8 \pm 0.1$ via dropwise addition of $1 \mathrm{M} \mathrm{HCl}$ over $4 \mathrm{~h}$. The mixture was left stirring overnight, subsequently dialyzed (MWCO =3,500 $\mathrm{g} \mathrm{mol}^{-1}$ ) against DIW for at least six $(6+\mathrm{h})$ cycles, and lyophilized. Polymers were stored as 20 or $40 \mathrm{wt} \%$ suspensions in PBS buffer (Bioland Scientific, CA) at $4^{\circ} \mathrm{C}$.

Synthesis of aldehyde-functionalized poly(oligo ethylene glycol methacrylate) ( $\left.P O_{x} A_{30}\right)$.

Aldehyde-functionalized $\mathrm{PO}_{10} \mathrm{~A}_{30}$ and $\mathrm{PO}_{100} \mathrm{~A}_{30}$ precursor polymers $(30 \mathrm{~mol} \%$ aldehyde, denoted $\mathrm{A}_{30}$ ) were synthesized following a previously reported procedure. ${ }^{24} \mathrm{AIBMe}(100 \mathrm{mg})$, $\mathrm{M}(\mathrm{EO})_{2} \mathrm{MA}\left(6.2 \mathrm{~g}\right.$ for $\mathrm{PO}_{10} \mathrm{~A}_{30}, 0 \mathrm{~g}$ for $\left.\mathrm{PO}_{100} \mathrm{~A}_{30}\right)$, OEGMA $\mathrm{A}_{500}\left(1.8 \mathrm{~g}\right.$ for $\mathrm{PO}_{10} \mathrm{~A}_{30}, 8.0 \mathrm{~g}$ for $\mathrm{PO}_{100} \mathrm{~A}_{30}$ ), DMAEAm (2.6 g for $\mathrm{PO}_{10} \mathrm{~A}_{30}, 1.2 \mathrm{~g}$ for $\mathrm{PO}_{100} \mathrm{~A}_{30} ; 30 \mathrm{~mol} \%$ to the total added $\left.\mathrm{OEGMA}_{500}+\mathrm{M}(\mathrm{EO})_{2} \mathrm{MA}\right)$ and TGA $\left(150 \mu \mathrm{L}\right.$ for $\mathrm{PO}_{10} \mathrm{~A}_{30}, 20 \mu \mathrm{L}$ for $\mathrm{PO}_{100} \mathrm{~A}_{30} ; 10$ wt $\%$ in dioxane) were added to a $250 \mathrm{~mL}$ round bottom flask. Dioxane $(40 \mathrm{~mL})$ was added to the reaction mixture, which was then purged with nitrogen for at least $20 \mathrm{~min}$. The flask was moved to a pre-heated oil bath at $75{ }^{\circ} \mathrm{C}$ under magnetic stirring to polymerize for $4 \mathrm{~h}$, after which the reaction was allowed to cool to room temperature. After solvent evaporation, $0.33 \mathrm{M} \mathrm{HCl}$ (200 $\mathrm{mL}$ ) was added to the oligo (ethylene glycol) methyl ether methacrylate/DMAEAm copolymer solution and left stirring for $24 \mathrm{~h}$ to facilitate conversion of acetal groups to aldehyde groups. The solution was dialyzed $\left(\mathrm{MWCO}=3,500 \mathrm{~g} \mathrm{~mol}^{-1}\right)$ against DIW for a minimum of six $(6+\mathrm{h})$ cycles and lyophilized to dryness. Polymers were stored as 20 or $40 \mathrm{wt} \%$ suspensions in PBS buffer at $4{ }^{\circ} \mathrm{C}$. 


\section{Chemical characterization of POEGMA precursors.}

Aqueous size exclusion chromatography (SEC) was performed using a Waters 515 HPLC pump, Waters 717 Plus autosampler, three Ultrahydrogel columns $(30 \mathrm{~cm}$ x $7.8 \mathrm{~mm}$ i.d. with exclusion limits of 0-3 kDa, 0-50 kDa and 2-300 kDa) and a Waters 2414 refractive index detector. A mobile phase consisting of $25 \mathrm{mM} \mathrm{N}$-cyclohexyl-2-aminoethanesulfonic acid (CHES) buffer, $500 \mathrm{mM} \mathrm{NaNO}_{3}$ and $10 \mathrm{mM} \mathrm{NaN}_{3}$ at a flow rate of $0.8 \mathrm{~mL} \mathrm{~min}^{-1}$ was used for all analyzed polymers except $\mathrm{PO}_{10} \mathrm{~A}_{30}$. The system was calibrated with narrow-dispersed PEG standards (106 to $584 \times 10^{3} \mathrm{~g} \mathrm{~mol}^{-1}$, Waters). N,N-dimethylformamide (DMF) SEC was used to analyze the $\mathrm{PO}_{10} \mathrm{~A}_{30}$ polymer, using a Waters 590 HPLC pump, three Waters Styragel columns (HR-2, HR-3, HR-4; $7.8 \times 300 \mathrm{~mm} ; 5 \mu \mathrm{m}$ particles) maintained at $40{ }^{\circ} \mathrm{C}$, and a Waters 410

refractive index detector maintained at $35^{\circ} \mathrm{C}$. Polymer samples were eluted at $0.5 \mathrm{~mL} \mathrm{~min}^{-1}$ with DMF containing $50 \mathrm{mM} \mathrm{LiBr}$. The system was calibrated with narrow molecular weight PEG standards (Waters). ${ }^{1} \mathrm{H}-\mathrm{NMR}$ was performed using a Bruker AVANCE $600 \mathrm{MHz}$ spectrometer with deuterated chloroform as the solvent. The degree of functionalization of the aldehyde containing precursors was determined by ${ }^{1} \mathrm{H}-\mathrm{NMR}$, while the degree of functionalization of the hydrazide containing precursors was determined by conductometric titration (Supporting Information, Table S1).

Preparation of cellulose nanocrystal (CNC) suspensions.

CNCs were generated through the acid-mediated hydrolysis of cotton ashless filter aid (40 g) using $64 \mathrm{wt} \%$ sulfuric acid $(700 \mathrm{~mL})$ at $45^{\circ} \mathrm{C}$ for $45 \mathrm{~min}$, as described previously. ${ }^{45}$ The cellulose solution was quenched in DIW, and centrifuged for $10 \mathrm{~min}$ at $6000 \mathrm{rpm}$. Water was decanted out, and the process was repeated until a pellet no longer formed. The cellulose suspension was dialyzed $(\mathrm{MWCO}=12-14 \mathrm{kDa})$ against DIW for a minimum of ten $(12+\mathrm{h})$ 
cycles. The CNC suspension was sonicated using a probe sonicator (Sonifier 450, Branson Ultrasonics, Danbury, CT) for three (15 min) cycles and stored as a $1 \mathrm{wt} \%$ suspension in its acid form $(\mathrm{pH}=3.2)$. Suspensions were concentrated up to $8.3 \mathrm{wt} \%$ by evaporation at ambient conditions, using gravimetric analysis to determine final weight-percent concentrations. Sulfate ester content was determined via conductometric titration (100 mg of CNC in $100 \mathrm{~mL}$ of $10 \mathrm{mM}$ $\mathrm{NaCl}$ as the analysis sample and $2 \mathrm{mM} \mathrm{NaOH}$ as the titrant), yielding a sulfur content of $0.42 \mathrm{wt}$ $\%\left(0.30\right.$ charges per $\left.\mathrm{nm}^{2}\right)$ in the CNCs. The charge per $\mathrm{nm}^{2}$ is calculated assuming a CNC length of $129 \mathrm{~nm}$, diameter of $10 \mathrm{~nm}$, and density of $1.6 \times 10^{-21} \mathrm{~g} \mathrm{~nm}^{-3}$. The apparent diameter of CNCs by dynamic light scattering (DLS, Zetasizer Nano, Malvern, UK) was $71 \mathrm{~nm}$ and the electrophoretic mobility was $-1.86 \times 10^{-8} \mathrm{~m}^{2} \mathrm{~V}^{-1} \mathrm{~s}^{-1}$ (measured on $0.25 \mathrm{wt} \%$ CNC suspensions in $10 \mathrm{mM} \mathrm{NaCl})$.

Preparation of injectable nanocomposite hydrogels.

Hydrogels were prepared by coextruding one or more $\mathrm{PO}_{\mathrm{x}} \mathrm{A}_{30}$ and $\mathrm{PO}_{\mathrm{x}} \mathrm{H}_{30}$ solutions at 16 wt \% in PBS buffer from a double barrel syringe equipped with a static mixer (MedMix, LSystem). CNCs were incorporated at different loadings $(0-4.95$ wt $\%$ total mass $)$ in equal amounts in both barrels. Mixtures were extruded into silicone molds, covered with a glass slide, and allowed to gel for $2+$ hours before any testing. Gelation time was monitored by a vial inversion test, whereby a hydrogel sample was extruded into a synthesis vial and inverted for 5 seconds; gelation time was defined as the time at which no flow was observed in the sample for the duration of inversion.

Five different series of POEGMA hydrogels were investigated. Two single-precursor gel systems were prepared using one $\mathrm{PO}_{\mathrm{x}} \mathrm{H}_{30}$ hydrazide and one $\mathrm{PO}_{\mathrm{x}} \mathrm{A}_{30}$ aldehyde-functionalized precursor polymer with the same transition temperature (i.e., $\mathrm{x}=10$ or $\mathrm{x}=100$ ). Three mixed- 
precursor systems $\left(\mathrm{PO}_{25 / 75}, \mathrm{PO}_{50 / 50}\right.$, and $\left.\mathrm{PO}_{75 / 25}\right)$ were also prepared by mixing a mass-based ratio of both hydrazide and aldehyde $\mathrm{PO}_{10}: \mathrm{PO}_{100}$ precursors at a total loading of $16 \mathrm{wt} \%$ in PBS (i.e., $\mathrm{PO}_{25 / 75}$ contains $80 \mathrm{mg}$ of $\mathrm{PO}_{10} \mathrm{H}_{30}$ and $240 \mathrm{mg}$ of $\mathrm{PO}_{100} \mathrm{H}_{30}$ in $2 \mathrm{~mL}$ of $\mathrm{PBS}$ in the hydrazide barrel, and $80 \mathrm{mg}$ of $\mathrm{PO}_{10} \mathrm{~A}_{30}$ and $240 \mathrm{mg}$ of $\mathrm{PO}_{100} \mathrm{~A}_{30}$ in $2 \mathrm{~mL}$ of $\mathrm{PBS}$ in the aldehyde barrel). Suffixes are used to indicate the $\mathrm{CNC}$ loading (i.e., $\mathrm{PO}_{100}-1.65$ indicates a sample containing $1.65 \mathrm{wt} \% \mathrm{CNC}$ (wet mass), or a mass loading ratio of POEGMA:CNC of 10:1). A list of all prepared hydrogels and nomenclature, along with the incorporated mole \% of each precursor monomer residue in the resulting hydrogels formed, is provided in Table 1. Note that all hydrogels are prepared using the same overall wt $\%$ of both hydrazide and aldehydefunctionalized POEGMA polymers (15 wt \%), precursor polymers that contain the same relative amount of reactive functional groups ( $30 \mathrm{~mol} \%$ on a total monomer basis), and a 1:1 mass ratio of hydrazide:aldehyde polymer; as such, the hydrazide:aldehyde ratio in each hydrogel prepared is maintained constant at 1:1. Note that ultra-high CNC loadings (4.95 wt \%) could only be tested in conjunction with $\mathrm{PO}_{100}$ series gels since the corresponding $\mathrm{PO}_{10}$ combinations gelled too quickly to be extruded and clogged the syringes. 
Table 1. Nomenclature, mol \% of long-chain $\left(\mathrm{OEGMA}_{500}\right)$, and short-chain $\left(\mathrm{M}(\mathrm{EO})_{2} \mathrm{MA}\right)$ as calculated by ${ }^{1} \mathrm{H}-\mathrm{NMR}$ (following method reported by Dong et. al. ${ }^{46}$ ), mol \% of functional monomer (hydrazide or aldehyde) present in the overall gel formulation, and approximate gelation times of POEGMA-CNC nanocomposite hydrogels investigated in this work.

\begin{tabular}{|c|c|c|c|c|c|c|}
\hline $\begin{array}{l}\text { POEGMA } \\
\text { Series }\end{array}$ & $\begin{array}{c}\text { Sample } \\
\text { Name }\end{array}$ & $\begin{array}{l}\text { Overall } \\
\text { OEGMA }_{500} \\
(\text { mol \%) }\end{array}$ & $\begin{array}{c}\text { Overall } \\
\text { M(EO) })_{2} \mathbf{M A} \\
(\mathbf{m o l} \%)\end{array}$ & $\begin{array}{c}\text { Overall } \\
\text { Functional } \\
\text { Monomer } \\
(\text { mol \%) }\end{array}$ & $\begin{array}{l}\text { CNCs } \\
\text { (wt \%) }\end{array}$ & $\begin{array}{c}\text { Gelation } \\
\text { Time }\end{array}$ \\
\hline \multirow{5}{*}{$\mathrm{PO}_{100}$} & $\mathrm{PO}_{100^{-}} 0$ & \multirow{5}{*}{70} & \multirow{5}{*}{0} & \multirow{5}{*}{30} & 0 & $\sim 40 \mathrm{~min}$ \\
\hline & $\mathrm{PO}_{100}-0.2$ & & & & 0.2 & $\sim 25 \mathrm{~min}$ \\
\hline & $\mathrm{PO}_{100}-0.96$ & & & & 0.96 & $\sim 15 \min$ \\
\hline & $\mathrm{PO}_{100}-1.65$ & & & & 1.65 & $\sim 8 \min$ \\
\hline & $\mathrm{PO}_{100}-4.95$ & & & & 4.95 & $\sim 30 \mathrm{~s}$ \\
\hline \multirow{4}{*}{$\mathrm{PO}_{25 / 75}$} & $\mathrm{PO}_{25 / 75^{-}}-0$ & \multirow{4}{*}{54} & \multirow{4}{*}{16} & \multirow{4}{*}{30} & 0 & $\sim 180 \mathrm{~s}$ \\
\hline & $\mathrm{PO}_{25 / 75^{-}}-0.2$ & & & & 0.2 & $\sim 60 \mathrm{~s}$ \\
\hline & $\mathrm{PO}_{25 / 75^{-}}-0.96$ & & & & 0.96 & $\sim 45 \mathrm{~s}$ \\
\hline & $\mathrm{PO}_{25 / 75}-1.65$ & & & & 1.65 & $\sim 30 \mathrm{~s}$ \\
\hline \multirow{4}{*}{$\mathrm{PO}_{50 / 50}$} & $\mathrm{PO}_{50 / 50}-0$ & \multirow{4}{*}{38} & \multirow{4}{*}{42} & \multirow{4}{*}{30} & 0 & $\sim 20 \mathrm{~s}$ \\
\hline & $\mathrm{PO}_{50 / 50^{-}} 0.2$ & & & & 0.2 & $\sim 15 \mathrm{~s}$ \\
\hline & $\mathrm{PO}_{50 / 50}-0.96$ & & & & 0.96 & $\sim 10 \mathrm{~s}$ \\
\hline & $\mathrm{PO}_{50 / 50^{-}}-1.65$ & & & & 1.65 & $\sim 5 \mathrm{~s}$ \\
\hline \multirow{4}{*}{$\mathrm{PO}_{75 / 25}$} & $\mathrm{PO}_{75 / 25^{-}}-0$ & \multirow{4}{*}{22} & \multirow{4}{*}{48} & \multirow{4}{*}{30} & 0 & $\sim 20 \mathrm{~s}$ \\
\hline & $\mathrm{PO}_{75 / 25}-0.2$ & & & & 0.2 & $\sim 15 \mathrm{~s}$ \\
\hline & $\mathrm{PO}_{75 / 25}-0.96$ & & & & 0.96 & $\sim 10 \mathrm{~s}$ \\
\hline & $\mathrm{PO}_{75 / 25}-1.65$ & & & & 1.65 & $\sim 5 \mathrm{~s}$ \\
\hline \multirow{4}{*}{$\mathrm{PO}_{10}$} & $\mathrm{PO}_{10}-0$ & \multirow{4}{*}{6} & \multirow{4}{*}{64} & \multirow{4}{*}{30} & 0 & $\sim 5 \mathrm{~s}$ \\
\hline & $\mathrm{PO}_{10}-0.2$ & & & & 0.2 & $<5 \mathrm{~s}$ \\
\hline & $\mathrm{PO}_{10^{-}} 0.96$ & & & & 0.96 & $<5 \mathrm{~s}$ \\
\hline & $\mathrm{PO}_{10}-1.65$ & & & & 1.65 & $<<5 \mathrm{~s}$ \\
\hline
\end{tabular}

Transmission electron microscopy (TEM) with cryogenic sectioning.

Hydrogel samples were prepared as described above and submerged in $10 \mathrm{mM}$ PBS to swell for at least $24 \mathrm{~h}$. A slow solvent exchange to ethanol was performed to minimize the collapse of pore structure, using increasing ethanol solutions of $0,10,20,30,40,50,75,95$ and $100 \mathrm{vol} \%$. Pieces of hydrogel samples were then quick frozen in liquid nitrogen and placed into a pre-cooled $\left(-145^{\circ} \mathrm{C}\right) \mathrm{FC} 4 \mathrm{E}$ cryochamber attached to an Ultracut $\mathrm{E}$ ultramicrotome (Reichert- 
Jung Wien, Austria). Thin sections (unstained) were cut with a diamond knife and placed onto Formvar-coated $\mathrm{Cu}$ grids which were allowed to warm to room temperature prior to imaging using a JEOL JEM 1200 EX TEMSCAN transmission electron microscope (JEOL, Peabody, MA) operating at an accelerating voltage of $80 \mathrm{kV}$.

\section{Swelling and degradation.}

Hydrogel discs with initial weight $W_{0}$ were placed in a 12 -well cell culture plate and completely submerged in $10 \mathrm{mM}$ PBS $(\mathrm{pH} 7.4,5 \mathrm{~mL})$ at time $\mathrm{t}=0$. Samples were then incubated at room temperature $\left(22^{\circ} \mathrm{C}\right)$, removed at specified time intervals, gently wicked to remove nonadsorbed solution, and weighed $\left(W_{t}\right)$. Discs were re-submerged in $5 \mathrm{~mL}$ PBS and weighed at subsequent time intervals until equilibrium was reached (generally $24 \mathrm{~h}$ ). The swell ratio (SR) was determined according to equation (1):

$$
S R=W_{t} / W_{0}
$$

$\mathrm{PO}_{100}$ hydrogel swelling was modeled using first order kinetics of the form $A=A_{0}(1-$ $\left.e^{(-k t)}\right)$, and $\mathrm{PO}_{10}$ hydrogel de-swelling was modeled using first order kinetics of the form $A=$ $A_{0}\left(e^{(-k t)}\right)$, allowing for fit of the swelling parameter $k$ for each hydrogel tested.

Accelerated degradation studies were also performed at $22{ }^{\circ} \mathrm{C}$ in $0.1 \mathrm{M} \mathrm{HCl}$ to enable comparisons between the acid-catalyzed hydrazone bond hydrolysis rates of different samples. Long term degradation studies were carried out in PBS at $37^{\circ} \mathrm{C}$. All experiments were repeated in at least triplicate, with results presented as an average value with error bars representing one standard deviation. 
Characterization of hydrogel rheological properties.

Rheology measurements were carried out at $22^{\circ} \mathrm{C}$ using a Mach-1 Mechanical Tester (Biomomentum Inc., Laval, QC, Canada) with parallel-plate geometry. All tested hydrogel discs had cylindrical geometry with a diameter of $12.7 \mathrm{~mm}$ and a height of $3.5 \mathrm{~mm}$. Unconstrained compression testing was performed to $25 \%$ of the sample height at a rate of $3 \%$ per second to determine the Young's modulus. Shear testing was also performed whereby samples were precompressed by $25 \%$ followed by strain sweeps with amplitudes ranging from 0.1 to 2.2 degrees at a frequency of $0.5 \mathrm{~Hz}$ to determine the linear viscoelastic region (LVE) of the hydrogel samples. Dynamic frequency sweeps were subsequently performed within the hydrogel LVE from 0.1 to $2.2 \mathrm{~Hz}$ to determine the shear storage modulus ( $\left.\mathrm{G}^{\prime}\right)$ of the samples. Samples were tested in at least triplicate; results are presented as an average value with error bars representing one standard deviation.

Quartz crystal microbalance with dissipation (QCM-D).

POEGMA adsorption to CNCs was studied using a Q-Sense E4 (distributed by Biolin Scientific for Q-Sense, Sweden) QCM-D instrument with four sensor channels. Q-Sense QSX 303 silicon dioxide-coated quartz crystal sensors with a resonant frequency of $5 \mathrm{MHz}$ (Biolin) were used for all measurements. Sensors were rinsed sequentially in DIW and ethanol, air dried, and UV-ozone treated for 20 minutes prior to use. A single drop of $2.35 \mathrm{wt} \% \mathrm{CNC}$ suspension was then loaded onto a sensor, spin coated at $4000 \mathrm{rpm}$ for $30 \mathrm{~s}$ (G3P Spincoat, Specialty Coating Systems Inc., IN), and baked overnight at $80{ }^{\circ} \mathrm{C}$ to make a uniform thin film. DIW was 
then used to rinse off any loosely bound CNCs, after which the sensors were baked for another 2 hours at $80^{\circ} \mathrm{C}$.

Prior to running an experiment, the QCM-D instrument was thoroughly cleaned (with washing sensors in place) by flowing a solution of 2 wt \% Hellmanex for 5 min, followed by DIW for $25 \mathrm{~min}$ (both at a flow rate of $100 \mu \mathrm{L} \mathrm{min}{ }^{-1}$ ) through all channels. CNC-coated sensors were then loaded, and allowed to swell overnight by running $10 \mathrm{mM}$ PBS through the instrument at $100 \mu \mathrm{L} \mathrm{min}{ }^{-1}$. After a stable baseline was observed for all CNC-coated sensors in PBS $(\leq 1 \mathrm{~Hz}$ change over $10 \mathrm{~min}), \mathrm{PO}_{\mathrm{x}} \mathrm{A}_{30}$ and $\mathrm{PO}_{\mathrm{x}} \mathrm{H}_{30}$ solutions $\left(0.1 \mathrm{mg} \mathrm{mL}^{-1}\right)$ were introduced at $100 \mu \mathrm{L}$ $\min ^{-1}$. Once the frequency change plateaued, sensors were rinsed with PBS $\left(100 \mu \mathrm{L} \mathrm{min}{ }^{-1}\right)$ to remove any unbound material. Experiments were concluded once a final stable baseline frequency in PBS was reached.

QTools software (version 3.0.12, Biolin) was used for data analysis of frequency and dissipation data (overtones 1, 3, 5, 7, 9 and 11). A rigid film assumption was made (valid given that the dissipation change is $\leq 10 \times$ the frequency change, $\Delta f)^{47}$, allowing use of the Sauerbrey equation to estimate adsorbed mass $(\Delta m)$ according to Equation 2:

$$
\Delta m=-C \cdot \Delta f / n
$$

Here, $C$ is a constant $\left(17.895 \mathrm{ng} \mathrm{cm}^{-2} \mathrm{~Hz}^{-1}\right)$ related to the quartz sensor \& geometry and $n$ is the overtone number. Surface coverage calculations were performed by calculating the Flory radius $\left(R_{F}\right)$ for each precursor polymer, as given by Equation 3:

$$
R_{F}=a N^{3 / 5}
$$

Here, $a$ is the monomer repeat unit length and $N$ is the number of monomers comprising the precursor polymer. A projected circular surface area was calculated from the $R_{F}$ value and 
multiplied by the number of polymers adsorbed onto the CNC-coated sensor, as estimated from the calculated adsorbed mass from QCM observations. This surface area was divided by the total surface area of the QCM-D sensor to give an estimate of surface coverage. DLS measurements were performed on suspensions of $0.225 \mathrm{wt} \%$ precursor polymer with $0.025 \mathrm{wt} \% \mathrm{CNC}(0.25 \mathrm{wt}$ $\%$ total) in $10 \mathrm{mM} \mathrm{NaCl}$ to further investigate adsorption and surface coverage.

\section{Isothermal titration calorimetry (ITC).}

Calorimetric titrations were performed on a Nano ITC Low Volume System (TA Instruments-Waters LLC, Newcastle, DE) as described previously. ${ }^{48}$ Briefly, experiments consisted of 20 successive $2.5 \mu \mathrm{L}$ injections of a POEGMA precursor polymer $(20 \mathrm{wt} \%$ in 10 $\mathrm{mM}$ PBS) into a reaction cell containing $170 \mu \mathrm{L}$ of a 0.9 wt $\% \mathrm{CNC}$ suspension in purified water (all solutions were degassed prior to testing). All experiments were performed at room temperature under constant stirring at $350 \mathrm{rpm}$. Titration heat signals were processed by NanoAnalyze software (TA Instruments-Waters LLC, Newcastle, DE). Data from the first injection was disregarded, omitting errors originating from the diffusion of titrant into the calorimetric cell. ${ }^{49}$ The heat of dilution of adding each POEGMA precursor polymer solution (prepared in PBS) into water not containing CNCs was used as a blank, with those measured heats of dilution subtracted from the enthalpies measured for each run. The molar heat of injection $\left(\Delta H, \mathrm{~kJ} \mathrm{~mol}^{-1}\right)$ was determined by integrating each individual injection peak, as demonstrated previously for other polymer systems adsorbing onto the surface of CNCs. ${ }^{50}$ In vitro cytotoxicity assay.

3 T3 fibroblast cells were plated on a 24-well plate with DMEM media (500 $\mu \mathrm{L})$ at a density of $3.0 \times 10^{4}$ cells per well and incubated for $24 \mathrm{~h}$ at $37^{\circ} \mathrm{C}$. Hydrogels were swollen and 
sterilized in $70 \%$ ethanol for 24 hours, washed three times in sterile PBS and then incubated in DMEM for 24 hours. Hydrogels were subsequently plated on top of 3T3 cells (covering almost the entire well) and then incubated for an additional 24 hours. Hydrogels were then removed from the wells, and cells were stained with a resazurin solution $(100 \mu \mathrm{L}$, prepared via the manufacturer's protocol) and incubated for an additional 4 hours. Fluorescence readings were recorded at $615 \mathrm{~nm}$ using a VICTOR 3 multi-label microplate readereone standard deviation.

Confocal microscopy of $3 T 3$ seeded hydrogels.

$\mathrm{PO}_{100}$ hydrogel precursors (both hydrazide and aldehyde) were pre-seeded with 3T3 fibroblast cells at a concentration of $1.2 \times 10^{4}$ cells per $\mathrm{mL}$ of prepolymer solution and subsequently extruded from a double barrel syringe into 8-well culture plates to form hydrogels with $\sim 30,000$ cells per well. Hydrogels were allowed to cure for $1 \mathrm{~h}$ at room temperature before adding $200 \mu \mathrm{L}$ DMEM to fully submerge the hydrogel samples, after which they were incubated at $37^{\circ} \mathrm{C}$ for $24 \mathrm{~h}$. Following, plates were gently washed with PBS and then stained with a calcein/ethidium homodimer-1 solution (live/dead assay) prepared according to the manufacturer-suggested protocol. Samples were viewed on a Zeiss LSM 510 laser scanning microscope (Oberkochen, Germany) using a $488 \mathrm{~nm}$ laser and a BP 505-530 nm emission filter (for calcein AM) or a $543 \mathrm{~nm}$ laser with a LP $560 \mathrm{~nm}$ emission filter (for ethidium homodimer1). Images were processed using Zeiss LSM Image Browser software (version 4.2) 


\section{RESULTS}

Synthesis and characterization of hydrogel precursors.

POEGMA precursor polymers were synthesized by free-radical copolymerization of diethylene glycol methacrylate $\left(\mathrm{M}(\mathrm{EO})_{2} \mathrm{MA}\right)$, oligoethylene glycol methacrylate $\left(\mathrm{OEGMA}_{500}\right)$ and $30 \mathrm{~mol} \%$ of a functional acrylate monomer to facilitate cross-linking (see Supporting Information, Figure $\mathrm{S} 1$ for chemical schemes ${ }^{23}$ ). Precursor polymers were tailored to have molecular weights between 15,000 and $30,000 \mathrm{~g} \mathrm{~mol}^{-1}$ so as to promote physiological clearance of hydrogel degradation products. The mole ratio of $\mathrm{M}(\mathrm{EO})_{2} \mathrm{MA}: \mathrm{OEGMA}_{500}$ was varied, as shown in Table 1, to yield precursor polymers with different ethylene oxide (EO) side chain lengths and LCST values but with similar degrees of functionalization and molecular weight (Supporting Information, Table S1, Figures S2-S5). ${ }^{25}$ Colloidally stable suspensions of cellulose nanocrystals with dimensions of $(60-240) \times(2-10) \mathrm{nm}$ (Supporting Information, Figure S6) were then mixed at varying concentrations (Table 1) with POEGMA precursor polymers prior to hydrogel extrusion.

Preparation of injectable hydrogels.

Nanocomposite POEGMA-CNC hydrogels were successfully prepared via co-extrusion of the reactive precursor polymer solutions from a double barrel syringe, as shown schematically in Figure 1. The POEGMA content in the hydrogel network was set at 16 wt \% (previously shown to facilitate effective gelation of POEGMA precursor polymers regardless of the OEGMA $_{500}: \mathrm{M}(\mathrm{EO})_{2} \mathrm{MA}$ ratio), ${ }^{24}$ while the $\mathrm{CNC}$ content was varied from 0 to $4.95 \mathrm{wt} \%$ (the latter representing the highest concentration of CNCs that could be extruded due to rheological limitations). The hydrogels cross-link via reversible covalent hydrazone bond formation between 
the POEGMA-bound hydrazide and aldehyde functional groups, physically entrapping the unmodified CNCs within the network.

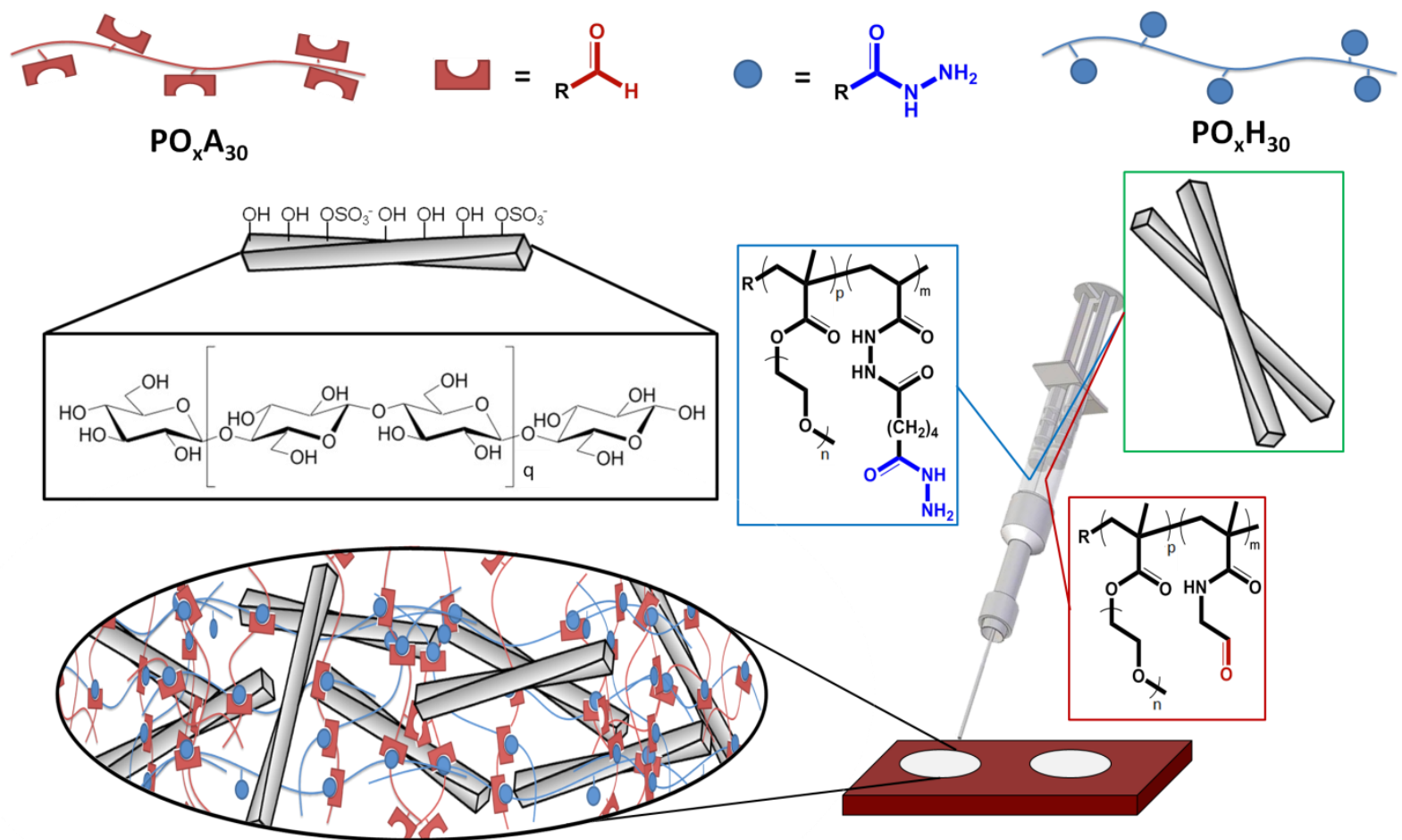

Figure 1. Schematic representation of hydrogel precursors and injectable POEGMA-CNC nanocomposite hydrogels (not drawn to scale). Precursor polymers with either short $(n=2)$ or long $(n=8-9)$ ethylene oxide side chains contain $30 \mathrm{~mol} \%$ functional hydrazide or aldehyde monomer (m). Overall molecular weight is similar for all polymers $\left(\mathrm{M}_{\mathrm{n}} \approx 20,000 \mathrm{~g} \mathrm{~mol}^{-1}\right)$.

CNC loading has significant effects on both the gelation time and visual appearance of the resulting hydrogels (Table 1 and Figure 2). Increasing the CNC concentration in the precursor mixture led to a systematic decrease in the gelation time of hydrogel discs, as measured using the vial inversion test. This trend is particularly noteworthy in hydrogels containing a higher fraction of $\mathrm{OEGMA}_{500}\left(\mathrm{PO}_{100}\right.$ and $\left.\mathrm{PO}_{25 / 75}\right)$, which have inherently longer gelation times (3 to $45 \mathrm{~min}$ ) than hydrogels with higher fractions of $\mathrm{M}(\mathrm{EO})_{2} \mathrm{MA}\left(\mathrm{PO}_{10}\right.$ and $\mathrm{PO}_{75 / 25}$ ) that have gelation times under $20 \mathrm{~s}$ independent of $\mathrm{CNC}$ content. $^{23}$ 
Visually, increasing the $\mathrm{CNC}$ loading led to a decrease in hydrogel transparency regardless of the POEGMA composition used (Figure 2). This decrease in gel transparency due to increased $\mathrm{CNC}$ loading is consistent with observations in other CNC-hydrogel systems ${ }^{40,44,51}$ and is attributed to the increasing turbidity of concentrated CNC suspensions. However, for all CNC concentrations tested, no visible aggregation of CNCs was observed in any of the hydrogels, a shortcoming of previous hydrogel systems with high $\mathrm{CNC}$ loadings ${ }^{44}$ that suggests a uniform dispersion of CNCs within the POEGMA matrix. Note that the inhomogeneities in Figure $2 \mathrm{~B}$ are due to the presence of air bubbles that become trapped in the gel due to the speed of the gelation process and do not represent any phase separation within the gel itself.
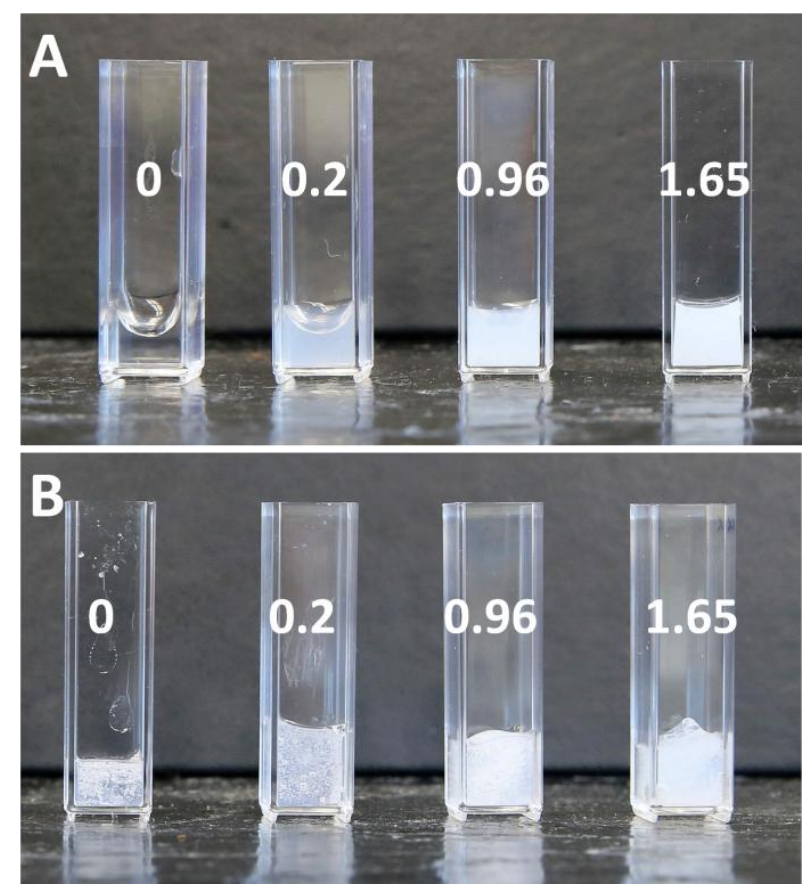

Figure 2. Optical appearance of $\mathrm{PO}_{100}(\mathrm{~A})$ and $\mathrm{PO}_{10}(\mathrm{~B})$ hydrogels with increasing $\mathrm{CNC}$ loading $(0,0.2$, $0.96,1.65 \mathrm{wt} \% \mathrm{CNCs}$, from left to right, respectively). 
Hydrogel swelling and degradation.

Swelling experiments were performed on single precursor POEGMA series hydrogels $\left(\mathrm{PO}_{10}\right.$ and $\left.\mathrm{PO}_{100}\right)$ in $10 \mathrm{mM} \mathrm{PBS}$ at $22{ }^{\circ} \mathrm{C}$ (Figure 3), with all gels normalized to an initial weight (16 wt \% polymer) to track the swelling ratio. All $\mathrm{PO}_{100}$-based hydrogels (which have no appreciable volume phase transition temperature in water) swelled to reach an equilibrium swelling value; as the $\mathrm{CNC}$ loading was increased, the equilibrium swelling value was reduced while the rate of swelling was increased (Figure 3A). For example, after 24 hours, $\mathrm{PO}_{100}-0$ reached a mass-based equilibrium swelling ratio of $3.2 \pm 0.1$, taking $\mathrm{t}_{50}=2.75$ hours to reach $50 \%$ of its total equilibrium swelling; in contrast, $\mathrm{PO}_{100}-4.95$ reached an equilibrium swelling value of only $1.30 \pm 0.01$ with a $\mathrm{t}_{50}=0.75$ hours (Table 2 and Figure $3 \mathrm{~A}$ ). The swelling rate constant $k$ also generally increases with increasing $\mathrm{CNC}$ loading except at extremely high CNC contents (Table 2), again suggesting that faster swelling kinetics are generally achieved in the presence of CNCs. In contrast, $\mathrm{PO}_{10}$-based hydrogels which exhibit volume phase transition temperatures of $\left.\sim 33^{\circ} \mathrm{C}\right)^{24}$ gradually de-swell to reach an equilibrium swelling value lower than the initial normalized hydrogel weight, consistent with a thermoresponsive hydrogel (Figure 3B). The presence of CNCs has a minimal effect on the equilibrium swelling ratio of the $\mathrm{PO}_{10}$ hydrogels, as the $\mathrm{PO}_{10^{-}} 0$ and $\mathrm{PO}_{10^{-}} 1.65$ hydrogels reach similar equilibrium swelling values after 24 hours $(0.79 \pm 0.02$ and $0.83 \pm 0.01$ respectively, Table 2$)$. However, consistent with the $\mathrm{PO}_{100}$ hydrogel series, increasing the $\mathrm{CNC}$ loading increases the rate of hydrogel de-swelling, as the $\mathrm{t}_{50}$ is notably shorter for $\mathrm{CNC}$ reinforced gels and $k$ increases as the $\mathrm{CNC}$ content is increased (Table 2 and Figure 3B). 
Table 2. Comparison of the swelling ratio (SR), time to reach $50 \%$ of total swelling $\left(\mathrm{t}_{50}\right)$ and rate constant $k$ for $\mathrm{PO}_{10}$ and $\mathrm{PO}_{100}$ series hydrogels with increasing CNC content. SR is calculated after 24 hours; $\mathrm{t}_{50}$ is interpolated.

\begin{tabular}{lrrr}
\hline \multicolumn{1}{c}{ Sample } & \multicolumn{1}{c}{ SR (-) } & $\mathbf{t}_{\mathbf{5 0}}(\mathbf{h r})$ & \multicolumn{1}{c}{$\boldsymbol{k}$} \\
\hline $\mathrm{PO}_{100}-0$ & $3.2 \pm 0.1$ & 2.75 & 0.25 \\
$\mathrm{PO}_{100}-0.2$ & $1.9 \pm 0.1$ & 1.75 & 0.40 \\
$\mathrm{PO}_{100}-0.96$ & $1.7 \pm 0.1$ & 1.75 & 0.38 \\
$\mathrm{PO}_{100}-1.65$ & $2.0 \pm 0.2$ & $<0.5$ & 1.12 \\
$\mathrm{PO}_{100}-4.95$ & $1.3 \pm 0.1$ & 0.75 & 0.41 \\
\hline $\mathrm{PO}_{10}-0$ & $0.79 \pm 0.02$ & 10.75 & 0.07 \\
$\mathrm{PO}_{10}-0.2$ & $0.80 \pm 0.01$ & 7.5 & 0.11 \\
$\mathrm{PO}_{10}-0.96$ & $0.81 \pm 0.02$ & 2.75 & 0.21 \\
$\mathrm{PO}_{10}-1.65$ & $0.83 \pm 0.01$ & 2.5 & 0.23 \\
\hline
\end{tabular}

Accelerated degradation studies were performed in $0.1 \mathrm{M} \mathrm{HCl}$ to investigate the comparative hydrogel network dissolution over time (Figure 3C and 3D). The presence of acid hydrolyzes the reversible POEGMA hydrazone cross-links, liberating free aldehyde and hydrazide-functionalized polymer chains and leading to a breakdown of the network structure. The networks degrade back to their starting precursor polymers, as previously shown through the direct overlap of GPC traces of the degradation products and starting precursor polymers. ${ }^{23}$ For both $\mathrm{PO}_{10}$ and $\mathrm{PO}_{100}$ series hydrogels, degradation is significantly slowed by the presence of CNCs. For $\mathrm{PO}_{100}-0$ gels, complete network degradation was achieved after only 50 minutes; in contrast, 300 minutes is required for full dissolution of the $\mathrm{PO}_{100}-4.95$ gels. $\mathrm{PO}_{10}$ series hydrogels degrade much slower than their $\mathrm{PO}_{100}$ series counterparts, attributable to both the higher crosslink density (due to shorter ethylene oxide side chains which impart less steric hindrance to cross-linking ${ }^{24}$ ) and lower water content of these gels. Still, $\mathrm{PO}_{10^{-}}-65$ gels resist dissolution longer than $\mathrm{PO}_{10}-0$ gels, again suggesting that $\mathrm{CNCs}$ play a role in enhancing the network structure. 
Ongoing long term degradation studies in $\mathrm{PBS}$ at $37^{\circ} \mathrm{C}$ (Supporting Information, Figure S7) show slow swelling of the $\mathrm{PO}_{100}$ hydrogels over a three month period, corresponding to the slow degradation of hydrazone bonds resulting in network expansion and increased water uptake; however, the hydrogels are still intact even after this period. A similar but even slower swelling (degradation) is observed $\mathrm{PO}_{10}$ hydrogels following their initial thermal de-swelling (consistent with previous observations in $\mathrm{CNC}$-free hydrogels), with $\mathrm{CNC}$ loading having no significant effect on long term degradation (similar to results observed in accelerated degradation studies).
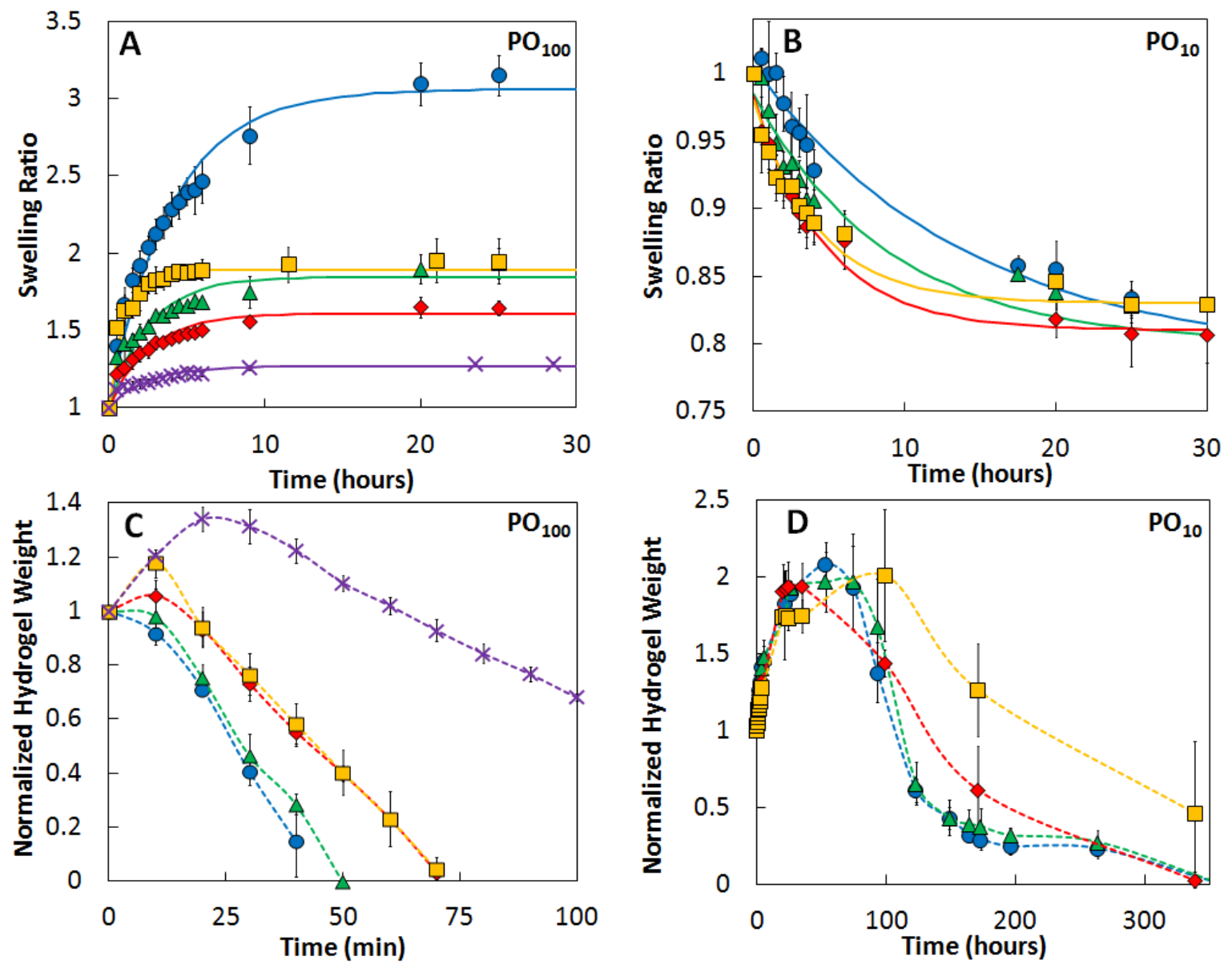

Figure 3. (A-B) Swelling kinetics in $10 \mathrm{mM}$ PBS at $22^{\circ} \mathrm{C}$ for $\mathrm{PO}_{100}(\mathrm{~A})$ and $\mathrm{PO}_{10}$ (B) series hydrogels; lines are modeled using first order kinetics; (C-D) Accelerated degradation kinetics in $0.1 \mathrm{M} \mathrm{HCl}$ at $22{ }^{\circ} \mathrm{C}$ for $\mathrm{PO}_{100}(\mathrm{C})$ and $\mathrm{PO}_{10}$ (D) series hydrogels; dashed lines are included as guides to the eye. Hydrogels contain $0 \mathrm{wt} \%$ (blue $\odot$ ), $0.2 \mathrm{wt} \%$ (green $\Delta$ ), $0.96 \mathrm{wt} \%$ (red $\diamond$ ), $1.65 \mathrm{wt} \%$ (yellow $\square$ ) and $4.95 \mathrm{wt} \%$ (purple $\times$ ) CNCs. Error bars represent one standard deviation of at least three replicates.

Hydrogel rheological properties. 
Mechanical testing was performed on all hydrogel series to determine the effects of adding CNCs. In all cases, incorporation of CNCs into the hydrogel networks resulted in gels with enhanced shear storage modulus G' (Figure 4). Gels with high $\mathrm{M}(\mathrm{EO})_{2} \mathrm{MA}$ content $\left(\mathrm{PO}_{10}\right.$ and $\mathrm{PO}_{75 / 25}$ ) have a high cross-link density and are thus inherently stronger than gels with high OEGMA 500 content $\left(\mathrm{PO}_{100}\right.$ and $\left.\mathrm{PO}_{25 / 75}\right)$, in which the longer PEG side-chains sterically hinder cross-linking. ${ }^{22}$ Correspondingly, $\mathrm{PO}_{10}$ and $\mathrm{PO}_{75 / 25}$ series gels show a significantly smaller mechanical enhancement ratio (MER) with increasing CNC loading as compared to $\mathrm{PO}_{100}$ and $\mathrm{PO}_{25 / 75}$ series gels (Table 3 ). $\mathrm{PO}_{10}-1.65$ showed a MER of $1.8 \pm 0.4$, whereas $\mathrm{PO}_{100}-1.65$ showed a MER of $11.0 \pm 1.2$. When the CNC loading was increased even further to $4.95 \mathrm{wt} \%$, the resulting $\mathrm{PO}_{100}-4.95$ gel exhibited a MER of $35.5 \pm 6.0$. (Note that $\mathrm{PO}_{10}$ gels with 4.95 wt $\%$ CNCs gelled too quickly to be extruded into molds for comparison.)

Unconstrained compression measurements to determine the Young's modulus showed similar general trends (Figure 4F). For $\mathrm{PO}_{100}$ gels, the incorporation of $1.65 \mathrm{wt} \% \mathrm{CNCs}$ resulted in a substantial 8-fold increase in Young's modulus versus POEGMA only controls. For the stiffer $\mathrm{PO}_{10}$ gels, the corresponding increase in Young's modulus for 1.65 wt \% CNC loading was only 1.2 times that of the controls. 
Table 3. Comparison of the shear storage modulus, G', and mechanical enhancement ratio (MER) for single and mixed precursor-based hydrogels with increasing CNC content. G' values are averaged across the LVE range investigated.

\begin{tabular}{lrr}
\hline Sample & \multicolumn{1}{c}{$\mathbf{G}^{\prime}(\mathbf{k P a})$} & \multicolumn{1}{c}{ MER (-) } \\
\hline $\mathrm{PO}_{100}-0$ & $1.1 \pm 0.1$ & $\mathrm{~N} / \mathrm{A}$ \\
$\mathrm{PO}_{100}-0.2$ & $7.2 \pm 0.4$ & $6.5 \pm 0.7$ \\
$\mathrm{PO}_{100}-0.96$ & $10.2 \pm 0.4$ & $9.3 \pm 0.9$ \\
$\mathrm{PO}_{100}-1.65$ & $12.1 \pm 0.7$ & $11.0 \pm 1.2$ \\
$\mathrm{PO}_{100}-4.95$ & $39.0 \pm 5.5$ & $35.5 \pm 6.0$ \\
\hline $\mathrm{PO}_{25 / 75}-0$ & $1.4 \pm 0.3$ & $\mathrm{~N} / \mathrm{A}$ \\
$\mathrm{PO}_{25 / 75}-0.2$ & $3.7 \pm 0.9$ & $2.6 \pm 0.8$ \\
$\mathrm{PO}_{25 / 75}-0.96$ & $7.1 \pm 0.6$ & $5.1 \pm 1.2$ \\
$\mathrm{PO}_{25 / 75}-1.65$ & $10.9 \pm 0.9$ & $7.8 \pm 1.8$ \\
\hline $\mathrm{PO}_{50 / 50}-0$ & $6.3 \pm 0.5$ & $\mathrm{~N} / \mathrm{A}$ \\
$\mathrm{PO}_{50 / 50}-0.2$ & $7.6 \pm 0.4$ & $1.2 \pm 0.1$ \\
$\mathrm{PO}_{50 / 50}-0.96$ & $12.3 \pm 1.0$ & $2.0 \pm 0.2$ \\
$\mathrm{PO}_{50 / 50}-1.65$ & $10.8 \pm 0.9$ & $1.7 \pm 0.2$ \\
\hline $\mathrm{PO}_{75 / 25}-0$ & $12.8 \pm 1.4$ & $\mathrm{~N} / \mathrm{A}$ \\
$\mathrm{PO}_{75 / 25}-0.2$ & $14.8 \pm 1.5$ & $1.2 \pm 0.2$ \\
$\mathrm{PO}_{75 / 25}-0.96$ & $15.6 \pm 1.4$ & $1.2 \pm 0.2$ \\
$\mathrm{PO}_{75 / 25}-1.65$ & $17.2 \pm 1.0$ & $1.3 \pm 0.2$ \\
\hline $\mathrm{PO}_{10}-0$ & $13.0 \pm 2.5$ & $\mathrm{~N} / \mathrm{A}$ \\
$\mathrm{PO}_{10}-0.2$ & $23.6 \pm 1.5$ & $1.8 \pm 0.4$ \\
$\mathrm{PO}_{10}-0.96$ & $25.6 \pm 2.2$ & $2.0 \pm 0.4$ \\
$\mathrm{PO}_{10}-1.65$ & $23.7 \pm 0.8$ & $1.8 \pm 0.4$ \\
\hline
\end{tabular}



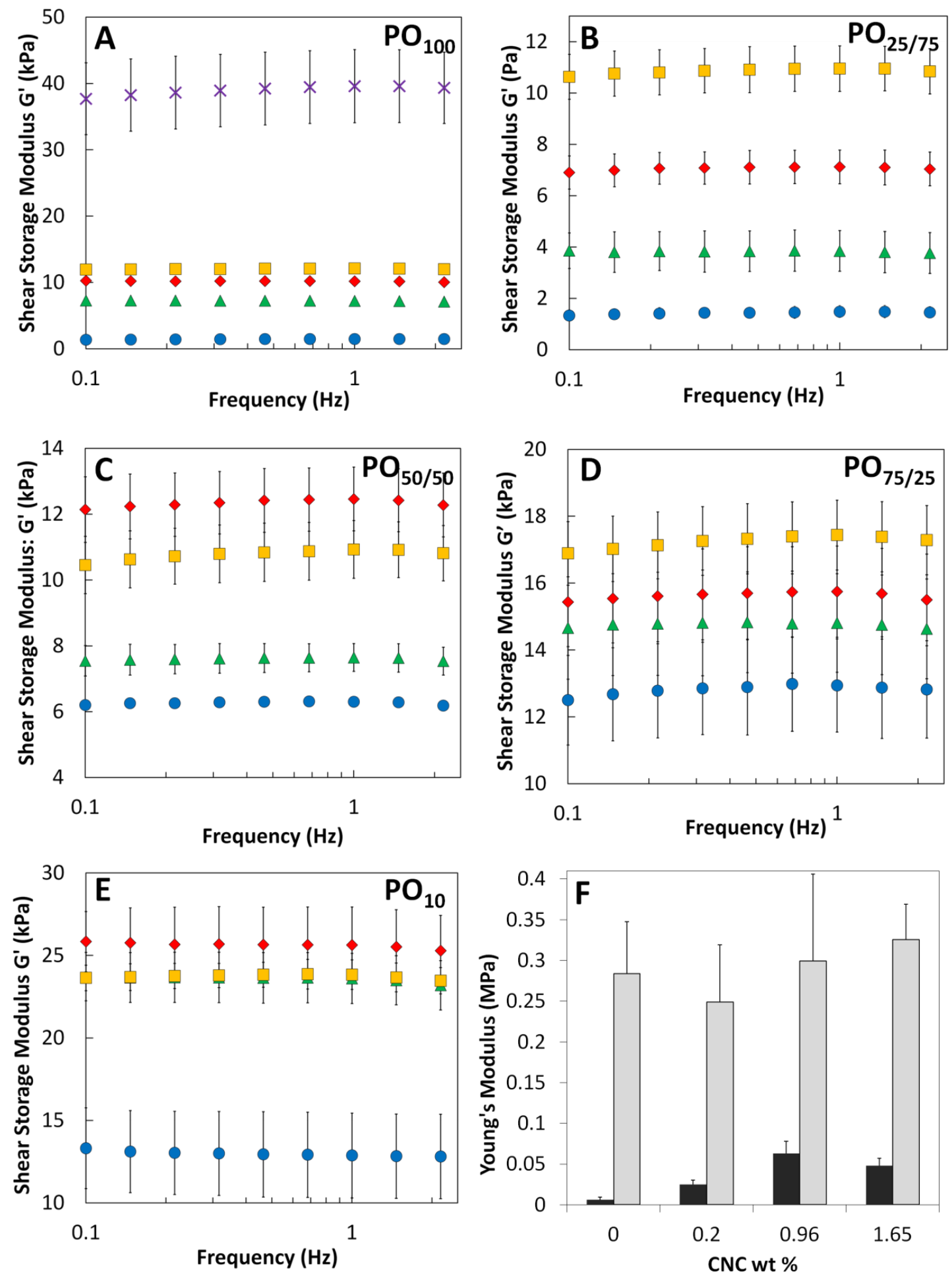

Figure 4. Frequency sweep measurements within the hydrogel $\mathrm{LVE}$ at $22^{\circ} \mathrm{C}$ for $\mathrm{PO}_{100}(\mathrm{~A}), \mathrm{PO}_{25 / 75}(\mathrm{~B})$, $\mathrm{PO}_{50 / 50}(\mathrm{C}), \mathrm{PO}_{75 / 25}(\mathrm{D})$, and $\mathrm{PO}_{10}(\mathrm{E})$ hydrogels containing 0 (blue $\odot$ ), 0.2 (green $\left.\Delta\right), 0.96$ (red $\left.\diamond\right), 1.65$ (yellow $\square$ ) and 4.95 (purple $\times$ ) wt \% CNCs; (F) Young's modulus determined under unconstrained compression for $\mathrm{PO}_{10}$ (dark grey) and $\mathrm{PO}_{100}$ (light grey) hydrogels. In all cases, error bars represent one standard deviation of at least three replicates. 
The mixed precursor hydrogel series displayed trends following the single precursor series with similar $\mathrm{OEGMA}_{500} / \mathrm{M}(\mathrm{EO})_{2} \mathrm{MA}$ content; with the major component of the mixed precursor gels holding the controlling influence on the resulting mechanical properties. $\mathrm{PO}_{25 / 75^{-}}$ 1.65 displayed a MER of $7.8 \pm 1.8$, closest to that observed for $\mathrm{PO}_{100}-1.65$ (MER $=11.0 \pm 1.2$ ); alternately, $\mathrm{PO}_{75 / 25^{-}} 1.65$ displayed a MER of $1.3 \pm 0.2$, closest to that observed for $\mathrm{PO}_{10^{-}} 1.65$ $(\mathrm{MER}=1.8 \pm 0.4)$. Note that all mixed precursor hydrogels displayed lower MER values than would be predicted based on a weighted average of the single precursor hydrogel components (Table 3), suggesting that the ability of CNCs to reinforce a mixed precursor hydrogel network is hindered by the mixed precursor hydrogel morphology. This trend is most obvious with the $\mathrm{PO}_{50 / 50}-1.65$ gels, which display a MER of $1.7 \pm 0.2$ that is significantly lower than would be predicted by the simple rule of mixtures $(\mathrm{MER} \approx 6.4)$.

To better understand the links between internal hydrogel structure and measured mechanical properties, TEM experiments were performed on cryo-sectioned $1.65 \mathrm{wt} \% \mathrm{CNC}$ networks of $\mathrm{PO}_{10}, \mathrm{PO}_{100}, \mathrm{PO}_{25 / 75}$ and $\mathrm{PO}_{75 / 25}$ hydrogels to view the $\mathrm{CNC}$ distribution within the networks (Figure 5). In the long ethylene oxide side chain single precursor hydrogel system $\left(\mathrm{PO}_{100}\right.$, Figure 5A), CNCs appear to be uniformly dispersed throughout the hydrogel matrix, even at ultra-high CNC loadings (Supporting Information, Figure S8). However for the short ethylene oxide side chain single precursor hydrogels whose gelation times are much faster, this uniform dispersity is not as evident (Figure 5B and cryo-TEM with liquid propane cryosectioning, Supporting Information, Figure S9). The mixed precursor hydrogels show distinct areas of higher and lower CNC density observed within the network (seen in Figures 5C and 5D as dark CNC-rich domains or light CNC-poor domains). Given that we have observed phase separation between the low-LCST $\left(\mathrm{PO}_{10}\right)$ and high-LCST $\left(\mathrm{PO}_{100}\right)$ domains of these mixed 
precursor hydrogels using small angle neutron scattering, ${ }^{25}$ this result suggests that CNCs may have more affinity for either the $\mathrm{PO}_{10}$-rich or $\mathrm{PO}_{100}$-rich phase inside the hydrogel. Note that individual $\mathrm{CNC}$ rods are harder to see in hydrogel systems containing $\mathrm{PO}_{10}$ precursor polymers, suggestive of potentially stronger interactions between $\mathrm{PO}_{10}$ and $\mathrm{CNCs}$ that may obscure the CNC shape upon imaging.

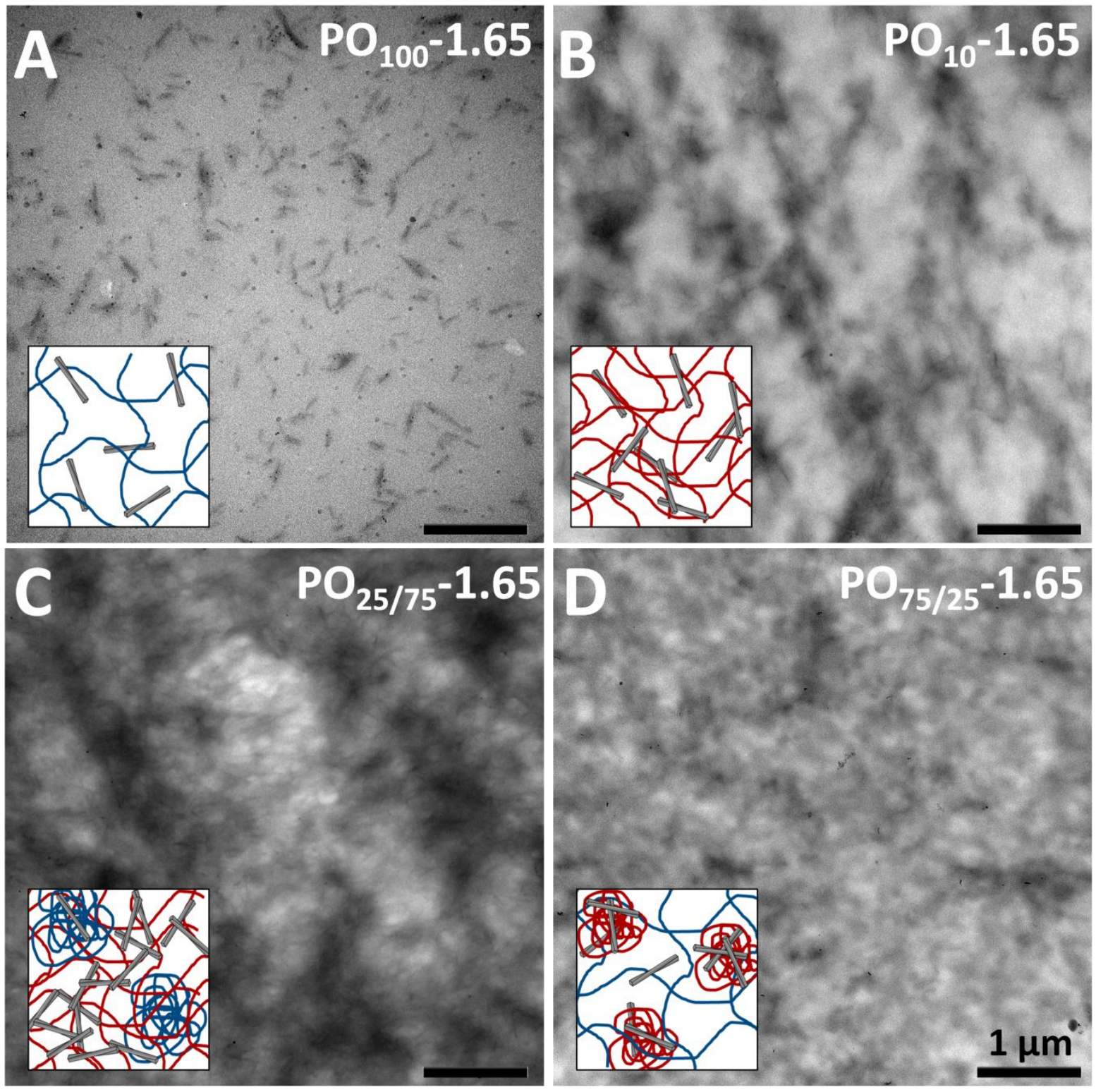

Figure 5. TEM images showing the distribution of CNCs in cryo-sectioned $\mathrm{PO}_{100}-1.65$ (A), $\mathrm{PO}_{10}-1.65$ (B), $\mathrm{PO}_{25 / 75}-1.65$ (C) and $\mathrm{PO}_{75 / 25}-1.65$ (D) mixed precursor hydrogels. Scale bars represent $1 \mu \mathrm{m}$. Inset images are schematic representations of the perceived $\mathrm{CNC}$ distribution within each hydrogel matrix 
relative to the identified morphologies of the POEGMA matrices, which have been studied previously through neutron scattering experiments. ${ }^{25}$ (not drawn to scale).

\section{POEGMA adsorption onto CNCs.}

QCM-D studies were performed to characterize adsorption of POEGMA precursors onto spin-coated CNC model films. Figure 6 shows the frequency change $\left(3^{\text {rd }}\right.$ overtone) over time associated with the adsorption of both $\mathrm{PO}_{10}$ and $\mathrm{PO}_{100}$ precursor polymers onto a CNC-coated sensor. Averaging the equilibrated baseline frequency values before and after POEGMA injection and taking the difference provides a measure of the frequency change associated with POEGMA adsorption (Table 4). The Sauerbrey equation was used to estimate the overall mass adsorbed, valid to use here since the dissipation change is less than $10 \%$ of the frequency change for all samples; this implies that the films are sufficiently thin and rigid. ${ }^{47}$

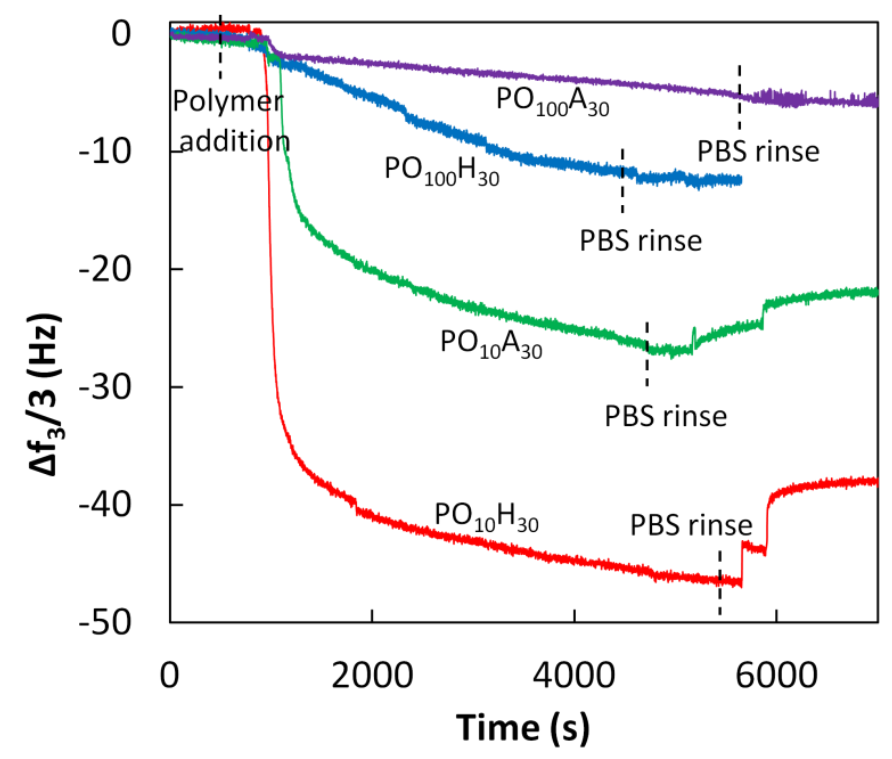

Figure 6. Normalized frequency change (third overtone) associated with POEGMA adsorption onto spincoated CNC films as measured by QCM-D. $\mathrm{PO}_{10} \mathrm{H}_{30}$ (red), $\mathrm{PO}_{100} \mathrm{H}_{30}$ (blue), $\mathrm{PO}_{10} \mathrm{~A}_{30}$ (green) and $\mathrm{PO}_{100} \mathrm{~A}_{30}$ (purple) precursor solutions were added after a stable baseline in PBS was reached, followed by a final PBS rinse after the frequency change began to plateau $\left(0.1 \mathrm{mg} \mathrm{mL}^{-1}\right.$ polymer solutions, $100 \mu \mathrm{L} \mathrm{min}^{-1}$ flow rate). 
Table 2. Frequency change and adsorbed mass (from Sauerbrey equation) associated with POEGMA adsorption onto CNC surfaces along with observed frequency divided by dissipation, as measured by QCM-D. Apparent diameters of CNCs with adsorbed polymer from DLS measurements are also shown. An estimate of surface coverage is calculated from the Flory radius $\left(R_{F}\right)$ of precursor polymers as described in Equation 3 (Supporting Information, Table S1).

\begin{tabular}{lrrrrr}
\hline Sample & $\begin{array}{c}\boldsymbol{\Delta} \mathbf{f}_{3} / \mathbf{3} \\
(\mathbf{H z})\end{array}$ & $\boldsymbol{\Delta} \mathbf{f}_{3} /\left(\mathbf{\Delta \mathbf { D } _ { 3 } \times \mathbf { 1 0 } \mathbf { 0 } ^ { - \mathbf { 6 } } )}\right.$ & $\begin{array}{c}\text { Adsorbed Mass } \\
\left(\mathbf{n g} / \mathbf{c m}^{2}\right)\end{array}$ & $\begin{array}{c}\text { Apparent Diameter } \\
(\mathbf{n m})\end{array}$ & $\begin{array}{c}\text { Surface } \\
\text { Coverage }(\boldsymbol{\%})\end{array}$ \\
\hline $\mathrm{CNC}$ & - & - & -5 & $71 \pm 1$ & - \\
$\mathrm{PO}_{10} \mathrm{H}_{30}$ & -38.2 & 16.9 & $684 \pm 8$ & $85 \pm 2$ & 2380 \\
$\mathrm{PO}_{10} \mathrm{~A}_{30}$ & -21.5 & 10.9 & $384 \pm 11$ & $85 \pm 4$ & 1480 \\
$\mathrm{PO}_{100} \mathrm{H}_{30}$ & -12.3 & 10.1 & $220 \pm 8$ & $81 \pm 2$ & 330 \\
$\mathrm{PO}_{100} \mathrm{~A}_{30}$ & -5.5 & 13.7 & $98 \pm 8$ & $81 \pm 2$ & 160 \\
\hline
\end{tabular}

$\mathrm{PO}_{10}$ series precursor polymers adsorb faster and in larger amounts to $\mathrm{CNCs}$ than the $\mathrm{PO}_{100}$ series precursor polymers; furthermore, both hydrazide-functionalized precursor polymers are adsorbed in larger amounts compared to their aldehyde counterparts, with approximately two-fold higher frequency changes observed for hydrazide relative to aldehyde precursor polymer adsorption (Table 4). It is also interesting to note that a PBS rinse removes some loosely bound $\mathrm{PO}_{10}$ precursor polymers from the $\mathrm{CNC}$-coated sensors, yet does not appear to remove any significant amount of $\mathrm{PO}_{100}$ precursor polymers. Surface coverage estimations suggest that precursor polymers are added in sufficient amounts to fully coat the CNC surfaces in all cases. However, mushroom conformation $\left(R_{F}\right.$-based) surface coverage estimates are approximately one order of magnitude higher for $\mathrm{PO}_{10}$ precursor polymers than for $\mathrm{PO}_{100}$ precursor polymers, suggesting that the adsorbed polymer conformation may be different between the short and long ethylene oxide side chain POEGMA systems. Collectively, these results suggest that all POEGMA precursor polymers have a clear affinity for $\mathrm{CNCs}$, with $\mathrm{PO}_{10}$ polymers adsorbing more than $\mathrm{PO}_{100}$ polymers. 
Dynamic light scattering (DLS) measurements were also conducted in order to further investigate POEGMA adsorption onto the surface of CNCs. Although DLS assumes an equivalent sphere (apparent) diameter in its size estimates, it has been successfully used in the past to determine relative differences in the apparent diameter of CNCs in suspension. ${ }^{52}$ The apparent diameter of unmodified CNCs was $71 \mathrm{~nm}$; adding either $\mathrm{PO}_{10}$ or $\mathrm{PO}_{100}$ precursor polymers at a 10:1 weight ratio (analogous to $\mathrm{PO}_{\mathrm{x}}-1.65$ hydrogels) results in a $10-14 \mathrm{~nm}$ increase in apparent diameter, with the measured apparent diameters for all treated hydrogels lying within error of each other ( $p>0.05$, Table 4). This result suggests that all POEGMA precursor polymers adsorb to CNCs, consistent with QCM-D observations.

Isothermal titration calorimetry was performed to better understand the driving forces responsible for POEGMA adsorption to CNCs. Figure 7 shows the net difference between the molar heat of injection of precursor polymers into a $\mathrm{CNC}$ suspension (derived by integrating the areas under the raw ITC data, shown for each polymer in Supporting Information, Figure S10) and the heat of dilution for each precursor polymer (again by integrating the areas under the dilution ITC peaks). Both aldehyde-functionalized precursor polymers show relatively small exothermic heats of injection of $-10.2 \mathrm{~kJ} \mathrm{~mol}^{-1}$ and $-7.6 \mathrm{~kJ} \mathrm{~mol}^{-1}$ for $\mathrm{PO}_{10} \mathrm{~A}_{30}$ and $\mathrm{PO}_{100} \mathrm{~A}_{30}$ respectively. In contrast, hydrazide-functionalized $\mathrm{PO}_{10} \mathrm{H}_{30}$ and $\mathrm{PO}_{100} \mathrm{H}_{30}$ display much larger and endothermic heats of injection of $110.6 \mathrm{~kJ} \mathrm{~mol}^{-1}$ and $68.6 \mathrm{~kJ} \mathrm{~mol}^{-1}$, respectively. 


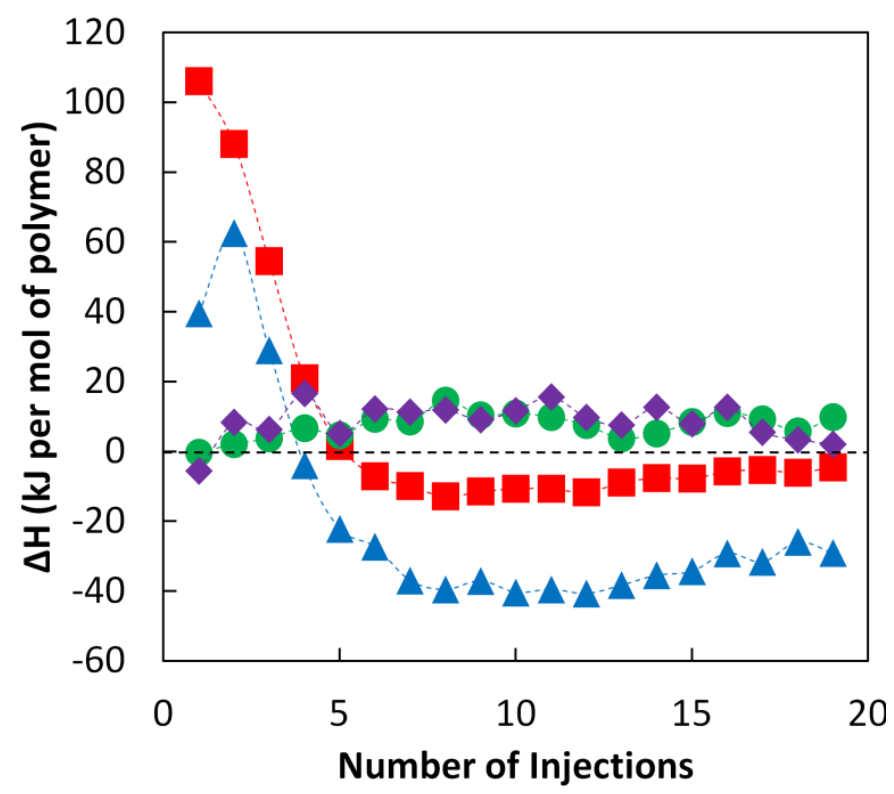

Figure 7. Molar heat of injection for the titration of $20 \mathrm{wt} \% \mathrm{PO}_{10} \mathrm{H}_{30}$ (red $\square$ ), $\mathrm{PO}_{100} \mathrm{H}_{30}$ (blue $\Delta$ ), $\mathrm{PO}_{10} \mathrm{~A}_{30}$ (green $\mathrm{O}$ ) and $\mathrm{PO}_{100} \mathrm{~A}_{30}$ (purple $\diamond$ ) precursor polymers into a $0.9 \mathrm{wt} \% \mathrm{CNC}$ suspension. The heat of dilution of each precursor polymer has been subtracted from the displayed titration curves.

Cell interactions with hydrogels.

Relative viability of $3 \mathrm{~T} 3$ mouse fibroblast cells exposed to both $\mathrm{PO}_{100}$ and $\mathrm{PO}_{10}$ hydrogels was studied using a resazurin-based assay to assess the cytotoxicity of the hydrogel (or leachates from the hydrogel) (Figure 8A). In all cases, no significant differences in cell viability were observed versus controls plated on tissue culture polystyrene, indicating no significant cytotoxicity toward $3 \mathrm{~T} 3$ cells.

The potential of these hydrogels for supporting cell growth was further assessed by suspending $3 \mathrm{~T} 3$ cells into $\mathrm{PO}_{100}$ polymer precursor solutions with increasing loadings of $\mathrm{CNCs}$ and co-extruding them to form hydrogels. Following $24 \mathrm{~h}$ of incubation in DMEM, cells remain viable inside the hydrogels independent of the $\mathrm{CNC}$ content and no dead cells are visible (Figures 8B-8D), indicating that nutrient transport throughout the hydrogel is sufficient and that the presence of CNCs does not negatively impact cell viability. 

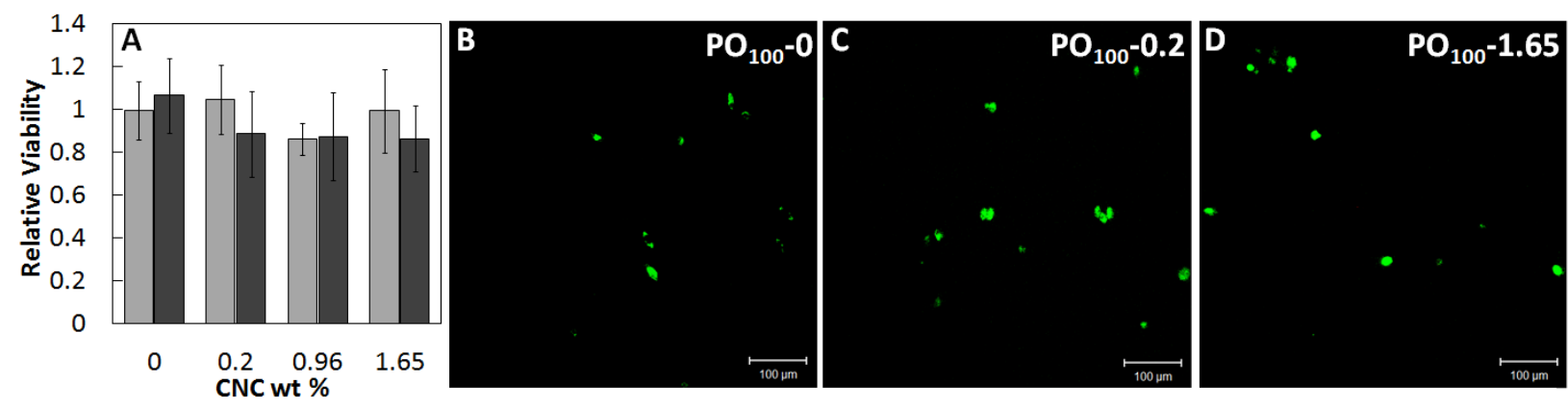

Figure 8. Relative viability of $3 \mathrm{~T} 3$ cells incubated with $\mathrm{PO}_{10}$ (light grey) and $\mathrm{PO}_{100}$ (dark grey) hydrogels having different $\mathrm{CNC}$ loading (A), and stacked confocal microscopy images of $\mathrm{PO}_{100}$ hydrogels extruded with 3 T3 cells stained with calcein AM and ethidium homodimer-1(B-D).

\section{DISCUSSION}

Combining CNCs with POEGMA precursor polymers with varying ethylene oxide side chain lengths results in hydrogels with significantly different properties, including gelation time, cross-link density, swelling, and mechanics. POEGMA hydrogels with primarily short ethylene oxide side chains $(\mathrm{n}=2)$ gel rapidly and have a high cross-link density that limits gel swelling and increases the storage modulus; conversely, longer ethylene oxide side chain POEGMA polymers $(n=8-9)$ act as steric inhibitors to gelation, hence reducing gelation times and decreasing cross-link densities to create highly swellable gels with lower moduli. The incorporation of $\mathrm{CNCs}$ is observed to consistently enhance mechanical properties, suppress equilibrium swelling, and lead to faster swelling kinetics and slower degradation relative to the corresponding POEGMA hydrogels without CNCs. Thus, CNC incorporation represents an alternative way to tune gel properties aside from changing the concentration of POEGMA precursor polymers and/or the degree of functionalization of POEGMA polymers (both of which we have previously demonstrated). ${ }^{23,24}$ We highlight that very low CNC weight fractions $(<5 \mathrm{wt}$ $\%)$ result in very large changes in gel properties. 
QCM-D results suggest that CNCs are physically incorporated into hydrogel networks not just through simple entanglement but also via the strong affinity of POEGMA for cellulose, forming an effective physical cross-link between the flexible polymers adsorbed to the rigid rodlike $\mathrm{CNC}$ reinforcing phase. The short side chain POEGMA series adsorbs more to CNCs than the long side chain polymers, consistent with the lower LCST and thus more compact nature of the short chain polymers which is speculated to drive adsorption to the non-charged and hydrophobic faces of CNCs (i.e., the 200 crystallographic plane which is free of hydroxyl groups $^{53}$ ) via hydrophobic interactions and imposes a lower entropic cost of polymer adsorption to CNCs.

In addition to short chain POEGMA precursors adsorbing more than long chain precursors, the (more hydrophilic) hydrazide-functionalized POEGMA precursor polymers also presumably adsorb to the hydrophilic $\mathrm{CNC}$ faces in larger amounts than the (less hydrophilic) aldehyde-functionalized POEGMA precursor polymers within each $\mathrm{PO}_{\mathrm{x}}$ series tested. ITC experiments show differences in the adsorption thermodynamics of aldehyde and hydrazidefunctionalized precursor polymers with $\mathrm{CNCs}$ that lend insight into this difference. The hydrazide precursor polymers show a net endothermic heat of injection, attributed to the effective dehydration (and thus effective reduction in LCST) upon hydrogen bond formation between polymer-bound hydrazide groups and $\mathrm{CNC}$-bound -OH groups and/or acid-base interactions between hydrazide groups and the CNC-bound sulfate ester groups that leads to breaking of polymer-water hydrogen bonds. This is consistent with previous observations in which cross-linking (i.e., converting the more hydrophilic and hydrogen bonding hydrazide group to a less hydrophilic and less hydrogen bonding hydrazone group) significantly reduces the temperature at which a phase transition occurs relative to the linear polymers. ${ }^{24}$ Given that 
the LCST of the $\mathrm{PO}_{10}$-hydrazide precursor polymer $\left(63.1^{\circ} \mathrm{C}\right)^{24}$ is significantly closer to the test temperature than that of the $\mathrm{PO}_{100}$-hydrazide precursor polymer $\left(>80^{\circ} \mathrm{C}\right)$, the magnitude of this dehydration transition is significantly higher for the $\mathrm{PO}_{10}$ system, consistent with the larger endotherm observed for $\mathrm{PO}_{10}$ in the ITC experiments. In contrast, both $\mathrm{PO}_{10}$ and $\mathrm{PO}_{100}$ aldehyde polymer precursors exhibit slightly exothermic binding isotherms, consistent with the higher potential for intramolecular hydrogen bonding, and thus the initially less hydrated nature of both aldehyde-functionalized polymers, which leads to a significantly lower net breaking of hydrogen bonds upon adsorption.

CNC surface coverage estimates from QCM-D measurements suggest that CNCs are fully coated with polymer upon mixing, with initial polymer adsorbing primarily in a mushroom conformation as previously reported for $\mathrm{PEG} .{ }^{54,55}$ For $\mathrm{PO}_{100}$ precursor polymers, surface coverage estimates based on $R_{F}$ calculations suggest that most polymers are bound in a stable mushroom conformation and are not removed during the PBS rinse. For $\mathrm{PO}_{10}$ precursor polymers, our calculation suggests that in a mushroom conformation, precursor polymers could fully saturate the CNC surface 10-fold; hence it is likely that the polymer collapses upon adsorption due to hydrogen bonding-driven dehydration and the subsequent lowering of the LCST of the polymer upon adsorption (as suggested by the ITC data), effectively lowering the polymers' $R_{F}$ values. Such a dehydration event could also allow for a much higher density of precursor polymer on the CNC surface, lower polymer mobility, and a less viscoelastic layer, consistent with the QCM-D dissipation values being the lowest for the strongest adsorbing $\mathrm{PO}_{10} \mathrm{H}_{30}$ system (Supporting Information, Figure S11). Note that, in all cases, dissipation increases linearly with adsorbed mass, suggesting that additional polymer chains do not pack tighter or change the overall viscoelastic properties of the adsorbed polymer layer. 
For all POEGMA series hydrogels tested, polymer adsorption onto CNC surfaces acts to (i) decrease the gelation time by effectively increasing the cross-link density in the hydrogel, via the formation of physical cross-links between polymers and CNCs in addition to the hydrazone chemical cross-links between polymers, (ii) decrease hydrogel swelling due to a reduction in polymer chain mobility close to the $\mathrm{CNC}$ surface (consistent with results previously reported) ${ }^{56}$ and (iii) increase the degradation time due to the formation of a tighter-packed network with non-hydrolyzable physical cross-links, a higher overall cross-link density, and less hydrolytically-accessible hydrazone bonds. These trends are more evident in the long chain $\mathrm{PO}_{100}$ series hydrogels which are inherently less cross-linked, making the additional degree of physical cross-linking provided by the POEGMA-CNC interactions more influential in determining the overall gel properties.

Similarly, a combination of POEGMA-CNC physical interactions and nanoparticle reinforcement effects results in an increase in modulus for all hydrogels tested when CNCs are incorporated into the hydrogel matrix. However, the magnitude of the increase in shear storage modulus varies significantly between the different POEGMA series investigated at the same $\mathrm{CNC}$ loadings, with the (weaker and lower effective cross-link density) $\mathrm{PO}_{100}$ series exhibiting a significantly larger enhancement in modulus than the (stronger and higher effective cross-link density) $\mathrm{PO}_{10}$ series hydrogels despite the higher adsorption of $\mathrm{PO}_{10}$ precursor polymers to $\mathrm{CNCs}$ evidenced by the QCM-D data. Of note, the ultra-high $\mathrm{CNC}$ loading $\mathrm{PO}_{100}-4.95$ hydrogel has a 35-fold higher $\mathrm{G}$ ' than the control $\mathrm{PO}_{100}-0$ hydrogel, which for tissue engineering applications would mechanically match much stiffer tissues including cartilage or pre-calcified bone to a degree not possible without the use of the CNC nanophase. ${ }^{57}$ 
Several other research groups have shown improved mechanical performance in injectable PEG-based hydrogels by incorporating nanoparticles. Gaharwar et al. studied the effects of adding hydroxyapatite nanoparticles within PEG hydrogels and demonstrated a 1.7fold increase in compressive modulus yet negligible increase in shear modulus even at $15 \mathrm{wt} \%$ hydroxyapatite nanoparticles $;{ }^{58}$ incorporation of $10 \mathrm{wt} \%$ silica nanospheres into the same hydrogels similarly demonstrated a low 1.5 -fold increase in the compressive modulus. ${ }^{59}$ Anisotropic nanoparticles have been reported to exhibit similarly low mechanical enhancements, with Chang et al. reporting a 1.6-fold increase in compressive modulus of PEG diacrylate hydrogels upon adding $10 \mathrm{wt} \%$ Laponite nanoparticles ${ }^{60}$ and Yang et al. demonstrating a 3.5fold increase in Young's modulus upon adding 1.2 vol \% CNCs to photo-cross-linked PEG hydrogels. ${ }^{61}$ As such, the dramatic increase in mechanical performance shown here (35-fold increase in modulus with $<5 \mathrm{wt} \% \mathrm{CNCs}$ ) is the largest improvement reported to date compared with other injectable/minimally invasive PEG-based hydrogels and is achieved by simple mixing of native $\mathrm{CNCs}$ into the gel matrix without the need for $\mathrm{CNC}$ surface modification.

Trends for the mixed precursor $\mathrm{PO}_{25 / 75}, \mathrm{PO}_{50 / 50}$ and $\mathrm{PO}_{75 / 25}$ series hydrogels are partly related to the cross-link density and adsorption tendencies of POEGMA to cellulose (consistent with the single component systems) but are also affected by phase separation of the precursor polymers and thus domain formation in the subsequent hydrogels. ${ }^{22,25}$ In particular, all mixed precursor polymer hydrogels exhibited significantly lower moduli than would be predicted based on a simple weighted average of the properties of the two constituent networks. Given the demonstrated higher affinity of $\mathrm{PO}_{10}$-based precursor polymers relative to $\mathrm{PO}_{100}$-based precursor polymers for CNC adsorption (Figure 6), we hypothesize that microphase domain separation of $\mathrm{PO}_{10}$ and $\mathrm{PO}_{100}$ precursor polymers leads to a correspondingly more heterogeneous incorporation 
of $\mathrm{CNCs}$ concentrated in the $\mathrm{PO}_{10}$-rich phase, thus reducing the capacity of CNCs to act as a reinforcing agent for the bulk hydrogel. This hypothesis is supported by the TEM results, in which CNCs appear more uniformly dispersed in (particularly) the $\mathrm{PO}_{100}$ and (to a lesser extent) the $\mathrm{PO}_{10}$ single precursor hydrogels (Figures $5 \mathrm{~A}$ and 5B) than the mixed precursor hydrogels, especially the $\mathrm{PO}_{25 / 75}-1.65$ hydrogel in which $\mathrm{PO}_{100}$ (the lower affinity phase for CNC adsorption) constitutes the continuous phase (Figure 5C).

Overall, CNC agglomeration is not observed for any of the hydrogels tested, significant since agglomeration is a documented issue for $\mathrm{CNCs}$ in nanocomposites and generally requires high energy mixing, solvent exchange steps, or surface modification of CNCs to be overcome. ${ }^{28}$ The adsorption of POEGMA onto CNCs and the compatibility of POEGMA and cellulose are believed to assist in the uniform distribution of $\mathrm{CNCs}$ and decrease the agglomeration tendencies of CNCs during gelation, even when only modest mixing is applied (using the double barrel syringe static mixer).

Previously, both $\mathrm{CNCs}^{32,35}$ and POEGMA hydrogels ${ }^{8,24}$ have been shown in various studies to be non-cytotoxic. Here, we show that POEGMA-CNC nanocomposite hydrogels are also non-cytotoxic, with CNC loading having no significant impact on cell viability. In addition, the demonstrated capacity to incorporate cells into precursor mixtures and then extrude into uniform hydrogels while maintaining cell viability independent of the CNC content suggests that POEGMA-CNC nanocomposites may be of use in biomedical applications, including tissue engineering and cell growth.

\section{CONCLUSION}


We have presented a highly tailorable injectable POEGMA-based hydrogel which possesses both covalent hydrazone cross-links between POEGMA precursors and physical crosslinks between CNCs and POEGMA to facilitate effective dispersion of CNCs and mechanical reinforcement of the hydrogel matrix. The adsorption of POEGMA precursor polymers onto the CNC surface can facilitate up to 35-fold increases in storage moduli versus POEGMA-only controls by adding only $5 \mathrm{wt} \%$ CNCs. The incorporation of well-dispersed CNCs leads to decreased POEGMA mobility giving stiffer, less swellable gels that degrade over longer time periods. Further, by changing the side chain length of the POEGMA precursor polymers, the adsorbed amount of POEGMA can be tuned, creating tighter packed or heterogeneous hydrogel morphologies. In all cases, the incorporation of CNCs does not negatively affect cell viability, indicating POEGMA-CNC nanocomposite hydrogels may offer particular utility in biomedical applications such as high-strength biodegradable tissue engineering scaffolds.

Supporting Information Available. Full characterization of POEGMA polymers, reaction scheme for the synthesis of aldehyde and hydrazide-functionalized POEGMA polymers, ${ }^{1} \mathrm{H}$ NMR spectra for hydrogel precursor polymers, an AFM height image of CNCs, long-term degradation data for hydrogels, $\mathrm{N}_{2}$ cryo-sectioned TEM image of ultra-high CNC loading $\mathrm{PO}_{100^{-}}$ 4.95 hydrogels, propane cryo-sectioned cryo-TEM image of $\mathrm{PO}_{10}-1.65$ hydrogel, raw isothermal titration calorimetry data, and plots of QCM-D dissipation versus adsorbed mass. This material is available free of charge via the Internet at http://pubs.acs.org.

\section{Acknowledgements.}

Funding from the Natural Sciences and Engineering Research Council of Canada (Discovery grants RGPIN 356609 and 402329) as well as NSERC CREATE-IDEM (Integrated Design of 
Extracellular Matrices) is gratefully acknowledged (grant 398058). The authors also thank X. Yang, E. Bakaic, H. Marway, Michael Reid, S. Kedzior, R. Mateen, M. Badv, and N. Smeets for useful discussions and instrument training, and professors R. Pelton, H. Stover, and R. Epand for use of equipment. Portions of this work were carried out in the Electron Microscopy Facility with the help of Marcia Reid (Faculty of Health Sciences) and the Biointerfaces Institute at McMaster University. 


\section{REFERENCES}

(1) Tirrell, R.L.D.A. Nature 2004, 428, 487-492

(2) Slaughter, B.V.; Khurshid, S.S.; Fisher, O.Z.; Khademhosseini, A.; Peppas, N.A. Adv. Mater. 2009, 21, 3307-3329

(3) Hoare, T.R.; Kohane, D.S. Polymer 2008, 49, 1993-2007

(4) Hoffman, A.S. Adv. Drug Delivery Rev. 2002, 54, 3-12

(5) McKee, J.R.; Hietala, S.; Seitsonen, J.; Laine, J.; Kontturi, E.; Ikkala, O. ACS Macro Lett. 2014, 3, 266-270

(6) Truong, V.X.; Ablett, M.P.; Richardson, S.M.; Hoyland, J.A.; Dove, A.P. J. Am. Chem. Soc. 2015, 137, 1618-1622

(7) Chau, M.; Sriskandha, S.E.; Pichugin, D.; Therien-Aubin, H.; Nykypanchuk, D.; Chauve, G.; Methot, M.; Bouchard, J.; Gang, O.; Kumacheva, E. Biomacromolecules 2015, 16, 2455-2462

(8) Bakaic, E.; Smeets, N.M.B.; Hoare, T. RSC Adv. 2015, 5, 35469-35486

(9) Pan, J.-f.; Yuan, H.-f.; Guo, C.-a.; Liu, J.; Geng, X.-h.; Fei, T.; Li, S.; Fan, W.-s.; Mo, X.-m.; Yan, Z.-q. RSC $A d v$. 2015, 5, 40820-40830

(10) Costa, A.M.S.; Mano, J.F. Eur. Polym. J. 2015, 72, 344-364

(11) Ye, E.; Chee, P.L.; Prasad, A.; Fang, X.; Owh, C.; Yeo, V.J.J.; Loh, X.J. Mater. Today 2014, 17, 194-202

(12) Kharkar, P.M.; Kloxin, A.M.; Kiick, K.L. J. Mater. Chem. B 2014, 2, 5511-5521

(13) Gao, W.; Xu, D.; Lim, D.W.; Craig, S.L.; Chilkoti, A. Polym. Chem. 2011, 2, 1561-1566

(14) Hu, Z.; Cai, T.; Chi, C. Soft Matter 2010, 6, 2115-2123

(15) Farnebo, S.; Woon, C.Y.L.; Schmitt, T.; Joubert, L.-M.; Kim, M.; Pham, H.; Chang, J. Tissue Eng., Part A 2014, 20, 1550-1561

(16) Cho, J.H.; Kim, S.-H.; Park, K.D.; Jung, M.C.; Yang, W.I.; Han, S.W.; Noh, Y.J.; Lee, J.W. Biomaterials 2004, 25, 5743-5751

(17) Huey, D.J.; Hu, J.C.; Athanasiou, K.A. Science 2012, 338, 917-921

(18) Yan, C.; Mackay, M.E.; Czymmek, K.; Nagarkar, R.P.; Schneider, J.P.; Pochan, D.J. Langmuir 2012, 28, 6076-6087

(19) Brandl, F.; Sommer, F.; Goepferich, A. Biomaterials 2007, 28, 134-146

(20) Lutz, J.-F. Adv. Mater. 2011, 23, 2237-2243

(21) Peng, B.; Grishkewich, N.; Yao, Z.; Han, X.; Liu, H.; Tam, K.C. ACS Macro Lett. 2012, 1, 632635

(22) Bakaic, E.; Smeets, N.M.B.; Dorrington, H.; Hoare, T. RSC Adv. 2015, 5, 33364-33376

(23) Smeets, N.M.B.; Bakaic, E.; Patenaude, M.; Hoare, T. Chem. Commun. 2014, 50, 3306-3309

(24) Smeets, N.M.B.; Bakaic, E.; Patenaude, M.; Hoare, T. Acta Biomater. 2014, 10, 4143-4155

(25) Smeets, N.M.B.; Bakaic, E.; Yavitt, F.M.; Yang, F.-C.; Rheinstadter, M.C.; Hoare, T. Macromolecules 2014, 47, 6017-6027

(26) Smeets, N.M.B.; Patenaude, M.; Kinio, D.; Yavitt, F.M.; Bakaic, E.; Yang, F.-C.; Rheinstadter, M.; Hoare, T. Polym. Chem. 2014, 5, 6811-6823

(27) Klemm, D.; Kramer, F.; Moritz, S.; Lindstrom, T.; Ankerfors, M.; Gray, D.; Dorris, A. Angew. Chem., Int. Ed. Engl. 2011, 50, 5438-5466

(28) Habibi, Y.; Lucia, L.A.; Rojas, O.J. Chem. Rev. 2010, 110, 3479-3500

(29) Colombo, L.; Zoia, L.; Violatto, M.B.; Previdi, S.; Talamini, L.; Sitia, L.; Nicotra, F.; Orlandi, M.; Salmona, M.; Recordati, C.; Bigini, P.; La Ferla, B. Biomacromolecules 2015, 16, 2862-2871

(30) Domingues, R.M.; Gomes, M.E.; Reis, R.L. Biomacromolecules 2014, 15, 2327-2346 
(31) Endes, C.; Mueller, S.; Kinnear, C.; Vanhecke, D.; Foster, E.J.; Petri-Fink, A.; Weder, C.; Clift, M.J.D.; Rother-Rutishauser, B. Biomacromolecules 2015, 16, 1267-1275

(32) Hanif, Z.; Ahmed, F.R.; Shin, S.W.; Kim, Y.K.; Um, S.H. Colloids Surf., B 2014, 119, 162-165

(33) Kovacs, T.; Naish, V.; O'Connor, B.; Blaise, C.; Gagne, F.; Hall, L.; Trudeau, V.; Martel, P. Nanotoxicology 2010, 4, 255-270

(34) Lin, N.; Dufresne, A. Eur. Polym. J. 2014, 59, 302-325

(35) Roman, M. Ind. Biotechnol. 2015, 11, 25-33

(36) Jorfi, M.; Foster, E.J. J. Appl. Polym. Sci. 2015, 132, 41719-41738

(37) Hosseinidoust, Z.; Alam, M.N.; Sim, G.; Tufenkji, N.; van de Ven, T.G. Nanoscale 2015, 7, 16647-16657

(38) Plackett, D.V.; Letchford, K.; Jackson, J.K.; Burt, H.M. Nord. Pulp Pap. Res. J. 2014, 29, 105118

(39) Atifi, S.; Su, S.; Hamad, W.Y. Nord. Pulp Pap. Res. J. 2014, 29, 95-104

(40) Yang, J.; Han, C.-R.; Xu, F.; Sun, R.-C. Nanoscale 2014, 6, 5934-5943

(41) Yang, J.; Han, C.-R.; Zhang, X.-M.; Xu, F.; Sun, R.-C. Macromolecules 2014, 47, 4077-4086

(42) Zhou, C.; Shi, Q.; Guo, W.; Terrell, L.; Qureshi, A.T.; Hayes, D.J.; Wu, Q. ACS Appl. Mater. Interfaces 2013, 5, 3847-3854

(43) He, X.; Xiao, Q.; Lu, C.; Wang, Y.; Zhang, X.; Zhao, J.; Zhang, W.; Zhang, X.; Deng, Y. Biomacromolecules 2014, 15, 618-627

(44) Yang, X.; Bakaic, E.; Hoare, T.; Cranston, E.D. Biomacromolecules 2013, 14, 4447-4455

(45) Beck-Candanedo, S.; Roman, M.; Gray, D.G. Biomacromolecules 2005, 6, 1048-1054

(46) Dong, Y.; Saeed, A.O.; Hassan, W.; Keigher, C.; Zheng, Y.; Tai, H.; Pandit, A.; Wang, W. Macromol. Rapid Commun. 2012, 33, 120-126

(47) Voinova, M.V.; Rodahl, M.; Jonson, M.; Kasemo, B. Phys. Scr. 1999, 59, 391-396

(48) Mateen, R.; Hoare, T. Int. J. Pharm. 2014, 472, 315-326

(49) Velazquez-Campoy, A.; Freire, E. Nat. Protoc. 2006, 1, 186-191

(50) Boluk, Y.; Zhao, L.; Incani, V. Langmuir 2012, 28, 6114-6123

(51) Chen, Y.; Xu, W.; Liu, W.; Zeng, G. J. Mater. Res. 2015, 30, 1797-1807

(52) Jiang, F.; Esker, A.R.; Roman, M. Langmuir 2010, 26, 17919-17925

(53) Kalashnikova, I.; Bizot, H.; Cathala, B.; Capron, I. Biomacromolecules 2012, 13, 267-275

(54) Drobek, T.; Spencer, N.D.; Heuberger, M. Macromolecules 2005, 38, 5254-5259

(55) Lee, H.; de Vries, A.H.; Marrink, S.J.; Pastor, R.W. J. Phys. Chem. B 2009, 113, 13186-13194

(56) Yang, J.; Zhao, J.J.; Xu, F.; Sun, R.-C. ACS Appl. Mater. Interfaces 2013, 5, 12960-12967

(57) Discher, D.E.; Mooney, D.J.; Zandstra, P.W. Science 2009, 324, 1673-1677

(58) Gaharwar, A.K.; Dammu, S.A.; Canter, J.M.; Wu, C.J.; Schmidt, G. Biomacromolecules 2011, $12,1641-1650$

(59) Gaharwar, A.K.; Rivera, C.; Wu, C.J.; Chan, B.K.; Schmidt, G. Mater. Sci. Eng., C 2013, 33, 1800-1807

(60) Chang, C.-W.; van Spreeuwel, A.; Zhang, C.; Varghese, S. Soft Matter 2010, 6, 5157-5164

(61) Yang, J.; Han, C.R.; Duan, J.F.; Xu, F.; Sun, R.-C. ACS Appl. Mater. Interfaces 2013, 5, 31993207 
For Table of Contents Use Only.

Enhanced mechanical properties in cellulose nanocrystal-poly(oligo ethylene glycol methacrylate) injectable nanocomposite hydrogels through control of physical and chemical cross-linking

Kevin J. De France, Katelyn J. W. Chan, Emily D. Cranston, Todd Hoare*

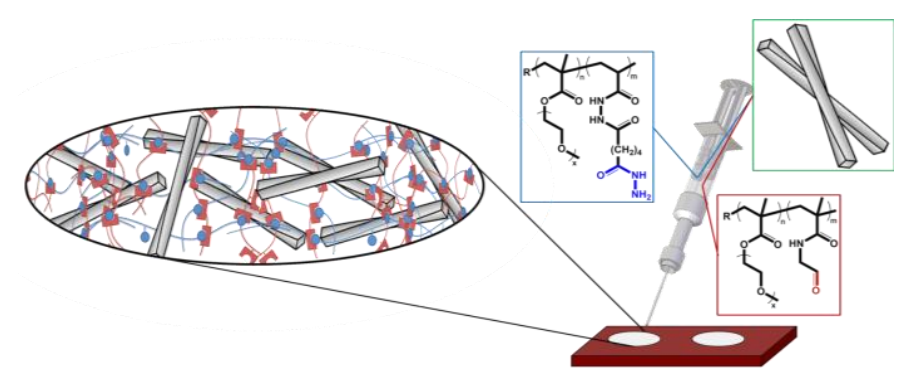

